\title{
Quasiclassical Trajectory Dynamics Study of Atomic Oxygen Collisions on an O- preadsorbed Graphite (0001) Surface With a New Analytical Potential Energy Surface
}

\author{
Víctor Morón a ${ }^{\text {a }}$ Ludovic Martin-Gondre ${ }^{\mathrm{b}, \mathrm{c}}$, Pablo Gamallo a ${ }^{\mathrm{a}}$ and Ramón Sayós ${ }^{\mathrm{a}}$ \\ ${ }^{a}$ Departament de Química Física and Institut de Química Teòrica i Computacional, Univ. Barcelona, \\ C/ Martí i Franquès 1, 08028 Barcelona (Spain) \\ ${ }^{b}$ Donostia International Physics Center (DIPC), P. Manuel de Lardizabal 4, 20018 San Sebastián (Spain) \\ ${ }^{c}$ Centro de Física de Materiales (CFM), Centro Mixto CSIC-UPV/EHU, P. Manuel de Lardizabal 5 , \\ 20018 San Sebastián (Spain)
}

\begin{abstract}
A new flexible periodic LEPS potential energy surface (FPLEPS) based on density functional theory data is constructed for the interaction of atomic oxygen with an O-preadsorbed graphite (0001) surface over a C-C bridge. New ingredients were added to the usual expression of the FPLEPS in order to take into account the entrance barriers, molecular orientation and morphology of the surface. A total of 563 DFT points were used to fit the Eley-Rideal (ER) reaction channel, achieving a root-mean-square deviation of $0.120 \mathrm{eV}$ for energies lower than $1 \mathrm{eV}$ over reactants. A quasiclassical trajectory (QCT) dynamics study has been performed at several initial conditions: collision energies $(0.01 \leq$ Ecol $\leq 2.0$ $\mathrm{eV})$, incident angles $\left(\theta \mathrm{v}=0^{\circ}, 45^{\circ}\right)$ and surface temperatures $(100 \leq$ Tsurf $\leq 900 \mathrm{~K})$. Also quasithermal and hyperthermal $(<$ Ecol $>=5.2 \mathrm{eV})$ conditions were considered. Eley-Rideal reaction and $\mathrm{O}$ reflection were the main processes, remaining the formed $\mathrm{O} 2$ molecules translationally and internally excited via the ER process. The calculated polar scattering angle distribution of hyperthermal atomic oxygen colliding onto a clean graphite surface matches better the experimental one for $\mathrm{O} / \mathrm{O} 2$ mixtures impinging on HOPG than those obtained for $\mathrm{O}$ colliding onto an O-preadsorbed surface.
\end{abstract}

Keywords: Quasiclassical trajectories, FPLEPS, Eley-Rideal reaction, O + O-graphite, potential energy surface, DFT calculations.

\section{Tables: 3 Figures: 10}

*Corresponding author: gamallo@ub.edu 


\section{Introduction}

Carbon fiber technology has already been used to replace many spacecraft components. In particular, fiber reinforced materials such as carbon and glass composites have the highest strength and stiffness to weight ratios among engineering materials. Carbon fiber composites, for example, are five times stiffer than steel for the same weight allowing for much lighter structures for the same level of performance. Since the strength of graphite improves with temperature up to about $2,760 \mathrm{~K}$, it is possible that vehicles, which must enter Earth's or Jupiter's atmosphere, or orbit very close to the Sun, may have some structural parts made out of carbon materials as graphite/graphene.

Satellites or spacecrafts in low Earth orbits (LEO), at approximately 160-2,000 km above Earth's surface, must travel very fast so that gravity will not pull them back into the atmosphere (i.e., around $7.5 \mathrm{~km} / \mathrm{s}$ ). At these conditions some of the main present gas species (i.e., $\mathrm{O} / \mathrm{O}_{2}$ ) collide with the spacecraft surface [1] at high collision energies (i.e., about $4.5 \pm 1.0 \mathrm{eV}$ ) producing all kind of heterogeneous reactions (i.e., etching, adsorption, recombination,...). Thus, it is very important for space industry to describe properly the interaction between $\mathrm{O} / \mathrm{O}_{2}$ with graphite and other related materials at these extreme conditions. Some experiments $[2,3,4]$ are performed with beams of $\mathrm{O}\left({ }^{3} \mathrm{P}\right)$ atoms with some extent of $\mathrm{O}_{2}\left(\mathrm{X}^{3} \Sigma_{\mathrm{g}}\right)$ that impinge over highly ordered/oriented pyrolitic graphite (HOPG) and analyze the chemical reactivity and morphological evolution of the surface. The main conclusion is that the graphite surface becomes functionalized with epoxide groups that can migrate across the surface. Moreover, incoming $\mathrm{O}$ atoms react at the surface to produce $\mathrm{O}_{2}$ molecules via an Eley-Rideal (ER) mechanism whereas incoming $\mathrm{O}_{2}$ molecules are only inelastically scattered.

Theoretical works regarding the interaction of $\mathrm{O} / \mathrm{O}_{2}$ with some graphitic surfaces (e.g., graphite $[5,6,7,8,9,10]$, graphene $[11,12,1314]$ and carbon nanotubes $[7,15,16])$ confirm the experimental observations. They point out that impinging $\mathrm{O}$ atom becomes chemically adsorbed on a bridge position 
between two adjacent $\mathrm{C}$ atoms of graphite or graphene, forming an epoxide group with an adsorption energy in the range of $0.95-3.4 \mathrm{eV}[5,6,7,8,9,14]$ for a basal graphite surface depending on the oxygen coverage and the level of the calculations. When the interaction is over a defective edge site on graphite surfaces, the adsorption energy increases considerably $(4.5-7.5 \mathrm{eV})[9,14]$. Another important feature of the atomic oxygen adsorption over graphite is the easy diffusion observed (energy barriers of 0.38 $\mathrm{eV}[5]$ and $0.36 \mathrm{eV}$ [6] for a coverage of $12.5 \%$ and $3.12 \%$, respectively), which are lower than the ones obtained for a graphene sheet $(0.58 \mathrm{eV}$ for a coverage of $16.7 \%$ [11]), that would imply a noticeable mobility of isolated adsorbed atom. In addition, we recently proposed a microkinetic model for $\mathrm{O} / \mathrm{O}_{2}$ over graphite [5]. This model used rate constants obtained from DFT and standard transition state theory for several processes occurring when $\mathrm{O} / \mathrm{O}_{2}$ mixtures collide over a clean graphite surface, showing a very low steady-state atomic coverage $(\theta<0.5 \%)$ and also very low atomic recombination coefficients $(\gamma)$ at quasithermal conditions $\left(\theta_{\mathrm{v}}, \mathrm{T}=300-1,000 \mathrm{~K}\right)$.

Hyperthermal collisions at normal incidence of O over graphene [2,13] and graphite [13] have been simulated by using DFT (PBE/DZP) data and the ReaxFF reactive force field, respectively, but without including the thermal bath. The surfaces were functionalized with preadsorbed $\mathrm{O}$ atoms or single vacancy defects. These dynamical simulations allow very long integration times (e.g., 150 ps [13]), and also increase the system size (every picosecond a new incoming oxygen atom impinges the surface, increasing thus the system size by one $\mathrm{O}$ atom per collision). In these conditions, it was observed that $\mathrm{O}$ adsorption (i.e., epoxide and carbonyl formation) and $\mathrm{O}_{2}$ formation via an ER mechanism were the main processes $(\mathrm{t}<45 \mathrm{ps})$ while inelastic collisions were very low. At longer times $\mathrm{CO} / \mathrm{CO}_{2}$ formation could also be observed and $\mathrm{C}$ sheet would be both broken and deformed. Nevertheless, neither $5 \mathrm{eV}$ oxygen atoms nor $10 \mathrm{eV}$ oxygen molecules are expected to cause sputtering from a pristine unfunctionalized surface [17] at least if no defect sites are previously formed. The absence of CO 
formation arising from pristine graphene at $3,000 \mathrm{~K}$ is also confirmed by DFT tight binding with dispersion (DFTB-D)-based molecular dynamics simulations [14].

The use of an analytical expression for the potential energy surface (PES) allows obtaining easily and efficiently the potential energy and its first order derivatives for performing fast dynamics calculations. In the last decades, the PLEPS (Periodic London-Eyring-Polanyi-Sato) function has been extensively used for studying the dissociative diatomic molecular adsorption mainly over several metallic systems $[18,19,20,21,22,23,24,25,26,27,28,29,30]$ and for the Eley-Rideal (ER) recombination of some particular systems (H/H-Cu(111) [31,32,33,34], H/D-Si(001) [35], H/H-graphite [36,37]). The popularity of PLEPS potential is due to the simplicity of its analytical form. However, the PLEPS model is known to be not flexible enough to describe the intricate structure of high-dimensional PES $[38,39,40]$. The use of only two adjustable parameters (Sato parameters) to fit a multi-dimensional PES (6D-PES for diatomic/surface systems) explains this major shortcoming. This is particularly true for heavy diatomic molecules interacting with surfaces that exhibit in many cases strongly corrugated PES $[41,42]$. Thus, although the PLEPS model was one of the reference models in the past, nowadays this method has become unreliable to deal with gas-surface reactions. An extension of the PLEPS model called FPLEPS (Flexible PLEPS) has been recently applied to $\mathrm{N}_{2} / \mathrm{W}(100,110)[40,43,44]$ and $\mathrm{O}_{2} / \mathrm{Cu}(100)$ [45], reaching a good level of accuracy. The FPLEPS is flexible enough to be adapted to various atom/diatom surface systems and for the study of various elementary reactions. Moreover, a new FPLEPS was recently provided [46] in parallel to an interpolated Modified Shepard one, for studying the $\mathrm{O}$ collisions with a pristine graphite (0001) surface giving dynamical information by means of classical trajectories in good agreement with the available experimental hyperthermal data [2]. 
The main goal of this work is to provide a new analytical FPLEPS PES for describing the O collisions with an O-preadsorbed graphite (0001) surface by using the previous developed PES for the O-atom interaction with the clean surface [46]. A quasiclassical trajectory (QCT) dynamics study is carried out with this new PES and compared with the available experimental data [2].

This paper is organized as follows: Section 2 provides a brief description about DFT and QCT calculations; Section 3 describes the FPLEPS PES construction and its main characteristics and Section 4 presents the main dynamical results and discussion, including the comparison with experimental data. Finally, Section 5 gives the summary and conclusions.

\section{Theoretical methods}

\section{A. DFT calculations}

Periodic density functional theory (DFT) calculations have been performed using the Vienna $a b$ initio simulation package (VASP) $[47,48,49,50]$. A detailed description of the DFT calculations was done in previous works $[5,46]$, thus only a few details are given here. The calculations are based on the generalized gradient approximation (GGA) with the revised Perdew-Burke-Ernzerhof functional (RPBE) [51]. The projector-augmented wave (PAW) technique within the frozen core approximation has been used to describe the electron-core interaction [52,53]. An energy cut-off of $550 \mathrm{eV}$ has been used in the plane-wave expansion and the Brillouin zone was integrated by using an $(11 \times 11 \times 1) k$ point mesh by means of the Monkhorst-Pack method [54]. All the slab calculations used a vacuum

around $15 \AA$, large enough to prevent significant interactions between periodic images. The energy convergence in the electronic self-consistent procedure was maintained below $10^{-6} \mathrm{eV}$ for all 
geometrical calculations performed within the rigid slab model. Due to the important role that spin plays in atomic oxygen description, all calculations were spin-polarized [5,7,9]. However, as the EleyRideal reaction does not imply necessarily a change in the spin state because both asymptotes correspond to triplet states (i.e., reactants $\left(\mathrm{O}_{(\mathrm{ad})}+\mathrm{O}_{(\mathrm{g})}\right)$ and products $\left(\mathrm{O}_{2(\mathrm{~g})}+\right.$ graphite)), this gives further support to the reliability of the present DFT approach. Moreover, our previous DFT study on O/graphite system [5, 46] showed a good agreement with available ab initio quantum molecular structure data and previous DFT data. Despite everything, we have carried out additional DFT calculations in order to calibrate the methodology used. Thus, non-periodic DFT calculations have also been performed with either UHF or RHF reference functions, using different basis sets and with a couple of hybrid functionals (PBE and B3PW91), by means of Gaussian 09 [55]. The cluster model used to simulate the graphite surface has been the pyrene molecule $\left(\mathrm{C}_{16} \mathrm{H}_{10}\right.$, cluster $\mathrm{A}$ in Ref. [16]). The results obtained for the adsorption energy, for the ER exothermicity and for the ER barrier are in good agreement with the results reported in this and in our previous work [5], taking into account the lack of periodicity in the cluster model. The differences between our values of adsorption energy and those reported in Refs. [7] and [9] can be rationalized by the fact of using different functionals. However, these DFT uncertainties could be reduced using more accurate $a b$ initio methods (e.g., CASPT2, Coupled Cluster,..), although DFT methods allow an easier treatment to model huge and periodic systems.

According to the previous study [5], molecular channel does not present any particular feature and is essentially repulsive close to the surface. A high endothermicity prevents the molecular dissociation, so the DFT data used to obtain the analytical surface was focused on the ER entrance channel. Since the most stable atomic adsorption site was the bridge one (B) for the atomic PES [46] as well as for DFT data [5], the configurations needed to be included into the PES fitting procedure consider also an 
oxygen atom $\left(\mathrm{O}_{\mathrm{A}}\right)$ fixed to the DFT calculated bridge minimum for a $(3 \times 3)$ supercell (i.e., $11.1 \%$ of coverage considering bridge sites). Working with such a big supercell increases considerably the number of atoms to be included in DFT calculations and consequently the computational cost, but it was necessary to avoid interactions between adsorbed atoms in contiguous cells. To ensure a proper description of the interaction of the incoming oxygen atom $\left(\mathrm{O}_{\mathrm{B}}\right)$ with the preadsorbed one, configurations at different $\phi$ angles (i.e., $0^{\circ}, 30,60$ and $90^{\circ}$, Fig. 1) were calculated for several impact

parameters in the range of $0.0 \AA<\mathrm{b}<3.0 \AA$ and considering the incoming atom at $\mathrm{Z}_{\mathrm{B}}$ values between $1.1 \AA$ and $3.1 \AA$. Thus, a total of 563 DFT configurations were calculated, whose contour plots are shown in the right panels of Fig. 2.

\section{B. QCT calculations}

A dynamical study involving the interaction of atomic oxygen over O-preadsorbed graphite surface was performed by means of the QCT method [56]. Several initial conditions were sampled in order to investigate state-specific, quasithermal and hyperthermal processes. State-specific $\left(\mathrm{E}_{\mathrm{col}}, \mathrm{T}_{\mathrm{surf}}, \theta_{\mathrm{v}}\right)$ calculations were carried out for fixed initial collision energies in the range of $0.01 \mathrm{eV} \leq \mathrm{E}_{\mathrm{col}} \leq 2.0 \mathrm{eV}$ and at two incident velocity angles $\left(\theta_{\mathrm{v}}=0^{\circ}\right.$ and $\left.45^{\circ}\right)$ for a given surface temperature $\mathrm{T}_{\text {surf. }}$. The atomic incoming velocity angle is defined with respect to the negative $\mathrm{Z}$ axis (e.g., $0^{\circ}$ for normal incidence) and its projection onto the X-Y plane (i.e., the azimuthal $\phi_{\mathrm{v}}$ angle) was uniformly sampled within the $0^{\circ}$ $-360^{\circ}$ interval.

Initial incoming atomic oxygen position $\left(\mathrm{X}_{\mathrm{B}}, \mathrm{Y}_{\mathrm{B}}\right)$ is randomly selected along the $(1 \times 1)$ unit cell meanwhile initial $Z_{B}$ position is set to $7.5 \AA$ where the interaction with surface is negligible. The 
preadsorbed oxygen atom $\left(\mathrm{O}_{\mathrm{A}}\right)$ was fixed initially at the equilibrium geometry of the $\mathrm{B} 1$ minimum found for the atomic FPLEPS surface [46] $\left(\mathrm{X}_{\mathrm{A}}=0.000 \AA, \mathrm{Y}_{\mathrm{A}}=0.713 \AA, \mathrm{Z}_{\mathrm{A}}=1.385 \AA\right.$, Fig. 1). To account for the energy exchanged and dissipated, a GLO model $[56,57,58,59]$ was used, including the surface and ghost particle motion into the Hamilton equations and by using the same optimum parameters, which were justified previously for $\mathrm{O} /$ graphite interaction [46]. These parameters were: $\omega_{\mathrm{i}, \mathrm{x}}$ $=\omega_{\mathrm{i}, \mathrm{y}}=10^{-3}$ and $\omega_{\mathrm{i}, \mathrm{z}}=3.4 \times 10^{-4}$ a.u. for $\mathrm{i}=1,2,3$ (oscillator frequencies), $\mathrm{m}=60 \mathrm{amu}$ (effective mass) and $\gamma_{\mathrm{g}, \mathrm{x}}=\gamma_{\mathrm{g}, \mathrm{y}}=\gamma_{\mathrm{g}, \mathrm{z}}=4.0 \times 10^{-4}$ a.u. (friction constants). The surface temperatures $\left(\mathrm{T}_{\mathrm{surf}}\right)$ studied were in the range of $100 \mathrm{~K} \leq \mathrm{T}_{\text {surf }} \leq 1,500 \mathrm{~K}$. The preadsorbed $\mathrm{O}$ atom is initially $(\mathrm{t}=0)$ displaced with the same coordinates of the surface particle $\left(\mathrm{X}_{\mathrm{s}}, \mathrm{Y}_{\mathrm{s}}, \mathrm{Z}_{\mathrm{s}}\right)$ to avoid any change in its potential. To make an easier initial selection for adatom coordinates, we put this at its equilibrium geometry (i.e., potential energy $V=0$ ) and then its total energy (i.e., $E=3 \mathrm{k}_{\mathrm{B}} \mathrm{T}_{\text {surf }}$ ) was introduced only as kinetic energy (i.e., sampling a Boltzmann distribution with $\mathrm{T}=2 \cdot \mathrm{T}_{\text {surf, }}[60]$ and references therein), assuming thus the virial theorem. We checked that this adatom was correctly thermalized together with the GLO bath during the trajectory and before the arrival of the incoming atom. The adsorbed atom remains around the equilibrium position and shows the usual oscillations for the kinetic and potential energies. The total energy is not constant due to the thermal bath dissipation effect.

The qctsurf code developed in our group was used to calculate the trajectories integrating the Hamilton equations of the system (included the GLO) using the Beeman algorithm. The time step used was $5 \times 10^{-17} \mathrm{~s}$, which ensures a total energy conservation along the trajectories lower than $1 \times 10^{-4} \mathrm{eV}$ in absence of the thermal bath. Total integration time was set to a maximum of $2.5 \mathrm{ps}$, long enough to obtain one of the possible exit channels defined as followed. Adsorption and reflection of the impinging atom was considered either if the preadsorbed atom remains adsorbed to the surface or if it desorbs, respectively. For atomic adsorption classification, the $\mathrm{Z}_{\mathrm{A}, \mathrm{B}}$ should be lower than $2.2 \AA$ and the 
number of total rebounds with the surface more than 8 , as was also set previously [46] for the atomic case over clean graphite. On the other hand, any of the oxygen atoms were considered reflected if either $Z_{\mathrm{A}}$ or $\mathrm{Z}_{\mathrm{B}}$ were higher than $7.6 \AA$ and the direction of the velocity vector pointed to the vacuum. The formation of the $\mathrm{O}_{2}$ molecule was also considered through two different channels either if the final molecule remains adsorbed or if it goes to the gas phase (i.e., ER reaction). The oxygen molecule was

considered formed when the internuclear distance $\mathrm{R}$ was lower than $2.0 \AA$ and dissociated for higher values than $3.0 \AA$. We also checked the formation of $\mathrm{O}_{2}$ molecules by either a direct (ER) mechanism or by a non-direct (hot atom) one. The criterion for a first tentative classification of some trajectories as ER or hot atom atomic recombination was based in the number of atomic rebounds previous to the $\mathrm{O}_{2}$ formation. Thus, reactive trajectories with more than two rebounds were classified as non-direct. Similarly as for atomic adsorption, when $Z_{\mathrm{cm}}$ was smaller than $2.2 \AA$ and the number of total rebounds with the surface was more than 8 , the event was classified as molecular adsorption.

The minimum number of total trajectories $\left(\mathrm{N}_{\mathrm{T}}\right)$ calculated for each condition was around 10,000, which leads to a standard error of $1-2 \%$ in ER probabilities.

\section{Analytical FPLEPS potential energy surface}

The complete expression used for describing the $6 \mathrm{D}$ potential $\mathrm{V}\left(\mathbf{R}_{\mathrm{A}}, \mathbf{R}_{\mathrm{B}}\right)$ of the two atoms $(\mathrm{A}, \mathrm{B})$ interacting with the graphite surface (Fig. 1) is defined as:

$$
\mathrm{V}\left(\mathrm{R}_{\mathrm{A}}, \mathrm{R}_{\mathrm{B}}\right)=\mathrm{U}_{\mathrm{As}}+\mathrm{U}_{\mathrm{Bs}}+\mathrm{U}_{\mathrm{AB}}-\sqrt{\mathrm{Q}_{\mathrm{AB}}+\left(\mathrm{Q}_{\mathrm{As}}+\mathrm{Q}_{\mathrm{Bs}}\right)^{2}-\mathrm{Q}_{\mathrm{AB}} \cdot\left(\mathrm{Q}_{\mathrm{As}}+\mathrm{Q}_{\mathrm{Bs}}\right)}+\sum_{\mathrm{i}=1}^{2} \mathrm{G}_{\mathrm{i}}
$$

where the positions of the two atoms $\mathrm{A}$ and $\mathrm{B}$ are respectively given by the vectors $\mathbf{R}_{\mathbf{A}}\left(\mathrm{X}_{\mathrm{A}}, \mathrm{Y}_{\mathrm{A}}, \mathrm{Z}_{\mathrm{A}}\right)$ and $\mathbf{R}_{\mathbf{B}}\left(\mathrm{X}_{\mathrm{B}}, \mathrm{Y}_{\mathrm{B}}, \mathrm{Z}_{\mathrm{B}}\right) . \mathrm{G}_{1}$ and $\mathrm{G}_{2}$ are two Gaussian functions introduced to improve the description of the full potential in the entrance valley in the same manner that in a previous work [40]. The terms $U_{i}$ and $Q_{i}$ 
represent respectively the Coulomb and exchange integrals for two-body systems and are associated with the atom-surface interaction ( $\mathrm{i}=\mathrm{As}$, Bs, described previously [46]) and the molecular interaction $(i=A B)$. These integrals have the usual form:

$$
\begin{aligned}
& \mathrm{U}_{\mathrm{i}}=\frac{\mathrm{D}_{\mathrm{i}}}{4\left(1+\Delta_{\mathrm{i}}\right)}\left[\left(3+\Delta_{\mathrm{i}}\right) \exp \left\{-2 \alpha_{\mathrm{i}}\left(\mathrm{R}_{\mathrm{i}}-\mathrm{R}_{\mathrm{i}}^{\mathrm{eq}}\right)\right\}-\left(2+6 \Delta_{\mathrm{i}}\right) \exp \left\{-\alpha_{\mathrm{i}}\left(\mathrm{R}_{\mathrm{i}}-\mathrm{R}_{\mathrm{i}}^{\mathrm{eq}}\right)\right\}\right]+\mathrm{f}_{\mathrm{i}} \\
& \mathrm{Q}_{\mathrm{i}}=\frac{\mathrm{D}_{\mathrm{i}}}{4\left(1+\Delta_{\mathrm{i}}\right)}\left[\left(1+3 \Delta_{\mathrm{i}}\right) \exp \left\{-2 \alpha_{\mathrm{i}}\left(\mathrm{R}_{\mathrm{i}}-\mathrm{R}_{\mathrm{i}}^{\mathrm{eq}}\right)\right\}-\left(6+2 \Delta_{\mathrm{i}}\right) \exp \left\{-\alpha_{\mathrm{i}}\left(\mathrm{R}_{\mathrm{i}}-\mathrm{R}_{\mathrm{i}}^{\mathrm{eq}}\right)\right\}\right]+\mathrm{f}_{\mathrm{i}}
\end{aligned}
$$

with $R_{i}=R$ for $i=A B$ and $R_{i}=Z_{A}, Z_{B}$ for $i=A s, B s$, and where $D_{i}, \alpha_{i}$ and $R_{i}^{\text {eq }}$ are the well known Morse parameters (i.e., dissociation energy, Morse shape parameter with the introduction of some particular flexibility and the equilibrium distance). The Sato parameters $\left(\Delta_{\mathrm{As}}=\Delta_{\mathrm{Bs}}, \Delta_{\mathrm{AB}}\right)$ are chosen to fit the main features of the ER DFT channel. The periodicity in the surface is achieved by assigning a $(\mathrm{X}, \mathrm{Y})$-dependence to the full set of parameters, concretely by means of Fourier expansions. Moreover, a switching function $f_{i}$ was also added to $U_{i}$ and $Q_{i}$ only for $i=A s$ and $B s$ (not for $i=A B$ ) in order to fit better the atomic adsorption barriers,

$$
\mathrm{f}_{\mathrm{k}}=\frac{1}{2} \lambda\left(\mathrm{X}_{\mathrm{k}}, \mathrm{Y}_{\mathrm{k}}\right) \cdot\left[1+\tanh \left(\vartheta\left(\mathrm{X}_{\mathrm{k}}, \mathrm{Y}_{\mathrm{k}}\right) \cdot \mathrm{Z}_{\mathrm{k}}+\chi\left(\mathrm{X}_{\mathrm{k}}, \mathrm{Y}_{\mathrm{k}}\right)\right)\right], \quad \mathrm{k}=\mathrm{O}_{\mathrm{A}}, \mathrm{O}_{\mathrm{B}}
$$

The dependence in $\left(\mathrm{X}_{\mathrm{k}}, \mathrm{Y}_{\mathrm{k}}\right)$ of the full set of parameters in Eq. (4) was ensured by means of a $5^{\text {th }}$ order Fourier expansion. All the details related with the oxygen-graphite interaction were developed previously [46].

For the molecular case, $i=A B$, a Morse like potential is obtained with $\alpha_{A B}(R)=\tilde{\alpha}_{0}+\tilde{\alpha}_{1} \cdot R$ in order to give more flexibility to the function. To ensure a correct description of $\mathrm{O}_{2(\mathrm{~g})}$ channel, the molecular parameters $\left(\mathrm{D}_{\mathrm{e}}\left(\mathrm{O}_{2}\right)=5.219 \mathrm{eV}, \tilde{\alpha}_{0}=1.541 \AA^{-1}, \tilde{\alpha}_{1}=0.956 \AA^{-1}, \mathrm{R}_{\mathrm{e}}\left(\mathrm{O}_{2}\right)=1.219 \AA\right)$ were obtained from the gas phase $\mathrm{O}_{2}$ potential determined from accurate coupled cluster calculations [61], which are in good agreement with experimental results (i.e., $\mathrm{D}_{\mathrm{e}}\left(\mathrm{O}_{2}\right)=5.213 \mathrm{eV}$ and $\mathrm{R}_{\mathrm{e}}\left(\mathrm{O}_{2}\right)=1.208 \AA$ [62]). 
The 2D Gaussian functions $\left(\mathrm{G}_{1}\right.$ and $\left.\mathrm{G}_{2}\right)$ improve the description of the entrance valley shape in the ER reaction,

$$
\mathrm{G}_{\mathrm{i}}\left(\phi, \mathrm{b}, \mathrm{Z}_{\mathrm{cm}}\right)=\mathrm{A}_{\mathrm{i}}(\phi) \exp \left\{-\left[\left(\frac{\left(\mathrm{b}-\mathrm{b}_{\mathrm{i}}(\phi)\right)^{2}}{\sigma_{\mathrm{i}}(\phi)}\right)+\left(\frac{\left(\mathrm{Z}_{\mathrm{cm}}-\mathrm{Z}_{\mathrm{cm}, \mathrm{i}}(\phi)\right)^{2}}{\sigma_{\mathrm{cm}, \mathrm{i}}(\phi)}\right)\right]\right\}, \quad \mathrm{i}=1,2
$$

where $Z_{c m}$ refers to the molecule centre of mass, and $b$ to the impact parameter (Fig. 1a). The other parameters (i.e., $\mathrm{A}_{\mathrm{i}}, \mathrm{b}_{\mathrm{i}}, \mathrm{Z}_{\mathrm{cm}, \mathrm{i}}, \sigma_{\mathrm{i}}$ and $\sigma_{\mathrm{cm}, \mathrm{i}}$ ) are $\phi$ dependent and are related with the height, position and the width of the Gaussian functions, whose optimal values are found by fitting the DFT data for each selected $\phi$ angle (i.e., $0^{\circ}, 30^{\circ}, 60^{\circ}$ and $90^{\circ}$ ), listed in Table I. It was necessary to fit also the Sato parameters for each $\phi$ angle in order to describe properly the complexity of the ER entrance channel. Fig. 2 shows the good agreement between DFT and FPLEPS contour plots for the four angles used for describing the ER channel. A periodic function $(\mathrm{P})$ has to be introduced to represent the $\phi$-dependence of the FPLEPS parameters. This function must accomplish $\mathrm{P}(\phi)=\mathrm{P}(-\phi)$ and $\mathrm{P}(\phi)=\mathrm{P}(\pi+\phi)$, which corresponds to the periodicity of the surface when atom $\mathrm{A}$ is preadsorbed over a determined bridge site (the B1 site is arbitrarily chosen in this work, cf. Fig. 1b). This function is defined for each parameter $\mathrm{P}_{\mathrm{j}}$ $(\mathrm{j}=1,12)$ as follows,

$$
\mathrm{P}_{\mathrm{j}}(\phi)=\mathrm{B}_{\mathrm{j} 0}+\mathrm{B}_{\mathrm{j} 1} \cos (2 \phi)+\mathrm{B}_{\mathrm{j} 2} \cos (4 \phi)+\mathrm{B}_{\mathrm{j} 3} \cos (6 \phi)
$$

The $\mathrm{B}_{\mathrm{ij}}$ parameters that solve the equation system are listed in Table II. It is worth noting that the previous strategy works when the preadsorbed atom is located over a particular bridge site (B1) but fails when trying to reproduce the correct behaviour over other bridge sites (B2 or B3). This is due to the different bridge sites are not equivalent with regard to the $\phi$ value within the framework of two atoms interacting on a graphite surface. Thus, for example the $\phi=0^{\circ}$ orientation over B1 site corresponds to $\phi=60^{\circ}$ and $120^{\circ}$ over B2 and B3 sites, respectively (assuming that T1 and T2 sites are 
fully equivalent). The simultaneous correct description of the three bridge sites requires considering a new Fourier expansion. In order to keep the good symmetry properties, it is necessary to include not only the three bridge sites in the new Fourier expansion but also nine additional sites (i.e., T1, T2, H, T1H1, T1H2, T1H3, T2H1, T2H2 and T2H3 defined in Fig. 1b). The idea is to make also a (X,Y)dependence of the molecular parameters (Sato and Gaussian parameters) via this new Fourier expansion (as for the atomic part but with different symmetry properties related to the two-atom interaction). A Fourier expansion series up to the $11^{\text {th }}$ order is used,

$$
\begin{aligned}
& P_{j}(X, Y)=C_{j 0}+C_{j 1}\left[\cos \left\{\frac{2 \pi}{a}(u+v)\right\}\right]+C_{j 2}\left[\sin \left\{\frac{2 \pi}{a}(u+v)\right\}\right]+ \\
& +C_{j 3}\left[\cos \left\{\frac{2 \pi}{a}(u)\right\}\right]+C_{j 4}\left[\sin \left\{\frac{2 \pi}{a}(u)\right\}\right]+C_{j 5}\left[\cos \left\{\frac{2 \pi}{a}(v)\right\}\right]+ \\
& +C_{j 6}\left[\sin \left\{\frac{2 \pi}{a}(v)\right\}\right]+C_{j 7}\left[\cos \left\{\frac{2 \pi}{a}(2 u+v)\right\}\right]+C_{j 8}\left[\cos \left\{\frac{2 \pi}{a}(u+2 v)\right\}\right]+ \\
& +C_{j 9}\left[\cos \left\{\frac{2 \pi}{a}(u-v)\right\}\right]+C_{j 10}\left[\cos \left\{\frac{4 \pi}{a}(u+v)\right\}\right]+C_{j 11}\left[\sin \left\{\frac{4 \pi}{a}(u+v)\right\}\right]
\end{aligned}
$$

where $C_{j i}(i=0$ to 11 and $j=1$ to 12$)$ represent the Fourier coefficients, $a=b=2.468 \AA$ is the cell parameter and (u,v) are the crystal coordinates (Fig. 1b), which are related with the orthogonal (X,Y) coordinates by

$$
u=X-\frac{Y}{\sqrt{3}} \quad, \quad v=\frac{2 Y}{\sqrt{3}}
$$

Before using the Fourier expansion for the Sato and Gaussian parameters, it is necessary to know the values of these parameters for the nine other sites that are included in the expansion. It was not necessary to perform additional DFT calculations since over these sites, the atomic adsorption is either weaker than over the bridge sites (T1, T2 sites) or simply not possible (potential is quite repulsive). Consequently, the value of the different parameters over these sites was not so important for the correct ER channel description. Thus, in order to ensure the surface symmetry requirements, an average value 
of the parameters for the three bridge sites was used for the nine other sites. Some checks were done in order to know the FPLEPS behaviour under this approximation, but the most important thing was to describe accurately the bridge sites, where the adsorption is much more favourable and where it is very likely that the ER processes happen.

One important aspect was to make sure that the PES was equivalent for any exchange of both atoms. The Fourier expansion needs to consider the position of one of the two atoms to calculate the parameters $\mathrm{P}_{\mathrm{j}}(\mathrm{X}, \mathrm{Y})$. However, if the coordinates of the A atom are chosen (i.e., the atom which is initially adsorbed) and latter during the dynamics the B atom replaces the other one, the determination of the parameters would still be performed as a function of the A coordinates instead of B ones, which is the really adsorbed atom. To avoid this problem, the atom/surface potential is calculated for both atoms $\left(\mathrm{V}_{\mathrm{As}}\left(\mathbf{R}_{\mathrm{A}}\right)\right.$ and $\left.\mathrm{V}_{\mathrm{Bs}}\left(\mathbf{R}_{\mathrm{B}}\right)\right)$ to decide about the adsorbed one. For instance, if $\mathrm{V}_{\mathrm{As}}\left(\mathbf{R}_{\mathrm{A}}\right)<\mathrm{V}_{\mathrm{Bs}}\left(\mathbf{R}_{\mathrm{B}}\right)$, the coordinates $\left(\mathrm{X}_{\mathrm{A}}, \mathrm{Y}_{\mathrm{A}}\right)$ are considered in the Fourier expansion (Eq. (8)). In addition, to avoid an abrupt change between $\mathrm{P}_{\mathrm{j}}\left(\mathrm{X}_{\mathrm{A}}, \mathrm{Y}_{\mathrm{A}}\right)$ and $\mathrm{P}_{\mathrm{j}}\left(\mathrm{X}_{\mathrm{B}}, \mathrm{Y}_{\mathrm{B}}\right)$, a switching function $\mathrm{f}_{\mathrm{AB}}$ was introduced,

$$
\begin{aligned}
& P_{j}\left(X_{A}, Y_{A}, X_{B}, Y_{B}\right)=\left(1-f_{A B}\right) P_{j}\left(X_{A}, Y_{A}\right)+f_{A B} \cdot P_{j}\left(X_{B}, Y_{B}\right) \\
& f_{A B}=\frac{1}{2}\left(1+\tanh \left[6.67\left\{V_{A s}\left(X_{A}, Y_{A}, Z_{A}\right)-V_{B s}\left(X_{B}, Y_{B}, Z_{B}\right)\right\}\right]\right)
\end{aligned}
$$

Finally, as angle $\phi$ is not defined for $b=0$ (i.e., perpendicular configuration), the determination of $P_{j}$ using Eq. (7) is not possible. This is only true for the Sato parameters since the Gaussian ones are not located in that region of space configuration. Therefore, it was necessary to include a new switching function for the two Sato parameters in the region close to perpendicularity $(b \approx 0)$. In this region $\mathrm{P}_{\mathrm{j}}$ is then defined by the expression,

$$
P_{j}=\left(1-f_{b}\right)\left[\left(\begin{array}{c}
0.0100 \\
-0.3500
\end{array}\right)\left(1-f_{R}\right)+f_{R}\left(\begin{array}{c}
-0.1583 \\
-0.1133
\end{array}\right)\right]+f_{b} P_{j}, \quad j=1,2
$$

where the top value is used when $\mathrm{j}=1$ (i.e., for $\Delta_{\mathrm{AB}}$ ) and the lower one in the case of $\mathrm{j}=2$ (i.e., for $\Delta_{\mathrm{As}}$, 
Bs, ); the $P_{j}$ term inside the equation is the one obtained in Eq. 10, whereas the $P_{j}$ on the left part is the final correct value. The switching functions used are,

$$
\begin{aligned}
& \mathrm{f}_{\mathrm{b}}=\frac{1}{2}(1+\tanh (20 \cdot \mathrm{b}-3.5)) \\
& \mathrm{f}_{\mathrm{R}}=\frac{1}{2}(1+\tanh (76.92 \cdot \mathrm{R}-117.35))
\end{aligned}
$$

where the numerical values inside the switching functions were chosen in order to give a connection as smooth as possible in the $\mathrm{b}$ and $\mathrm{R}$ intervals considered. Thus, $\mathrm{f}_{\mathrm{b}}$ is only different of 1 in the limit $\mathrm{b} \rightarrow 0$ $\AA$, otherwise its value is the unity and $\mathrm{P}_{\mathrm{j}}(\mathrm{j}=1,2)$ parameters remain unchanged.

Details about the binding energy of the $\mathrm{O}$ atom to the surface over different sites are reported and discussed widely in our previous work [46]. As a summary, only the asymptotic energy values for the resulting FPLEPS PES are listed in Table III.

Fig. 2 shows the comparison between the FPLEPS PES and the DFT data used for fitting the ER channel at four $\phi$ angles $\left(0^{\circ}, 30^{\circ}, 60^{\circ}\right.$ and $\left.90^{\circ}\right)$ for the approaching of one $\mathrm{O}$ atom to the surface when the other one is already preadsorbed over a bridge site at $Z_{\mathrm{B}}=1.384 \AA$. The analytical PES reproduces quite well the DFT data and gives a correct behaviour not only in the calculated areas but also seems to be reliable for other configurations. The root-mean-square deviation (RMSD) obtained taken into account energies lower than $5 \mathrm{eV}$ respect $\mathrm{O}_{(\mathrm{ad})}+\mathrm{O}_{(\mathrm{g})}$ asymptote is $0.312 \mathrm{eV}$ (357 points), but decreases until a value of $0.120 \mathrm{eV}$ for energies lower than $1 \mathrm{eV}$ (268 points).

Fig. 3 shows the interaction of one oxygen atom adsorbed on different bridge sites (B1, B2 and B3 at a distance of $Z_{A}=1.384 \AA$ ), with an incoming one at different $X_{B}, Y_{B}$ values and at a fixed $Z_{B}=3.0$ $\AA$. As expected, an exact equivalency of the three sites is obtained. Moreover, the most favoured areas for approaching the incoming $\mathrm{O}$ atom are the neighbouring bridge sites.

For the preadsorbed $\mathrm{O}$ atom onto $\mathrm{B} 1$ site (Fig. 3a), the favoured approaching angles for the 
incoming atom are $60^{\circ}, 120^{\circ}, 240^{\circ}$ and $300^{\circ}$. It is important to note that these favoured approaching angles are obtained for $Z_{B}=3.00 \AA$. Indeed, if the distance to the surface diminishes the approach over the closest neighbour bridges is not preferred at all and the incoming atom tends to get adsorbed over a non-adjacent bridge site (Fig. 3d), as predicted in the previous DFT theoretical work [5]. The analysis of the ER channel shows a very small ER energy barrier of 0.025 eV located at $d\left(\mathrm{O}_{A} \mathrm{O}_{B}\right)=2.344 \AA$, $\mathrm{d}\left(\mathrm{O}_{\mathrm{A}} \mathrm{C}\right)=2.184 \AA,<\mathrm{CO}_{A} \mathrm{O}_{\mathrm{B}}=128.9^{\circ}$, for a $\phi$ approaching angle of $43.5^{\circ}$ and with frequencies $1551.3 \mathrm{i}$, $140.9,355.3,424.3,47.5,575.9 \mathrm{~cm}^{-1}$. This TS is close to the DFT stationary point obtained previously $(0.10 \mathrm{eV}$ or $0.076 \mathrm{eV}$ including or not the $\mathrm{ZPE}[5])$ at $\mathrm{d}\left(\mathrm{O}_{\mathrm{A}} \mathrm{O}_{\mathrm{B}}\right)=2.024 \AA$ for a collinear approach (i.e., zero impact parameter), that presented two imaginary frequencies, therefore indicating the existence of a smaller energy barrier. Moreover, additional DFT cluster model calculations for a collinear approach confirm that this barrier should be lower than $0.04 \mathrm{eV}$ (PBE/cc-pVTZ).

\section{QCT dynamical results}

\section{A. State-specific conditions}

Probabilities for each of the exit channels were calculated for two incident angles $\left(\theta_{\mathrm{v}}=0^{\circ}\right.$ and $\left.45^{\circ}\right)$ at several initial collision energies between $0.01 \mathrm{eV}$ and $2.0 \mathrm{eV}$. Results plotted in Fig. 4 show that the reflection of the impinging atom and the ER reaction are the two main processes observed in all the conditions explored.

For normal incidence without thermal bath (Fig. 4a), the ER probability firstly increases with $\mathrm{E}_{\text {col }}$ and latter decreases at high collision energies, without showing threshold energy in agreement with the negligible energy barrier found in the PES. The reflection follows just the contrary behaviour. Atomic 
adsorption is much less important and becomes open at medium energies while atomic desorption is only produced at very high energies, where the impinging atom destabilizes the preadsorbed one.

When off normal incidence is considered (Fig. 4b), ER reaction probability decreases considerably compared with normal incidence results (Fig. 4a) becoming the atomic reflection more important than the ER reaction. Moreover, desorption processes are now more significant, probably because the parallel component of the kinetic energy of the impinging atom favours the removing of the adatom.

The effects of the surface temperature introduced through the thermal bath (Figs. 4c-f) are small. Only some differences at high collision energies are observed. Thus, the reflection process is slightly attenuated since the atomic adsorption becomes larger. This fact is due to an appreciable energy transfer from incoming atom to the surface, hence enhancing the atomic trapping.

Since the preadsorbed $\mathrm{O}$ atom remains weakly linked to the graphite surface $\left(\mathrm{E}_{\mathrm{ad}}=0.68\right.$, Table III), the possibility of extracting this adatom from the surface with an incoming atom is easier than when the adatom is strongly adsorbed $\left(\mathrm{E}_{\mathrm{ad}}=3.05,2.35\right.$ and $2.8 \mathrm{eV}$ for $\mathrm{H}$ over $\mathrm{W}(100,110)$ [63], $\mathrm{Cu}(110)$ [64] and $\mathrm{Pd}(111)$ [65], respectively or $\mathrm{E}_{\mathrm{ad}}=4.75 \mathrm{eV}$ for $\mathrm{O}$ over $\beta$-cristobalite [66]). Moreover, the fact that the $\mathrm{O}_{2}$ bond is strong $\left(\mathrm{D}_{\mathrm{e}}\left(\mathrm{O}_{2}\right)=5.219 \mathrm{eV}\right)$ leads to a very important exothermicity for the ER reaction of $\mathrm{O}$ over graphite surface. These facts are the reason for obtaining such a high ER probability in comparison with other similar gas-surface systems.

The adsorption and reflection probabilities are lower than the ones obtained for a clean graphite (0001) surface [46], because now the preadsorbed oxygen occupies the bridge site (so, there are not any free bridge site inside the $(1 \times 1)$ unit cell for adsorption $)$ and also due to the existence of other processes (i.e., ER, desorption), that obviously compete with the adsorption and reflection.

The analysis of the initial positions of the impinging atom shows that trajectories leading to ER reaction generally start at positions close to the preadsorbed atom because they allow the interaction 
between both oxygen atoms to form the $\mathrm{O}_{2}$ molecule, in agreement with PES topology (Fig. 2). Furthermore, the atomic adsorption process without desorption of the preadsorbed atom is only possible when the $\mathrm{R}$ distance is long enough to consider the interaction almost negligible; in this case, the incoming atom is behaving as if it was interacting with a clean surface. The analysis of the final position of these trajectories shows that this atom finally adsorbs over bridge sites located close to the starting position of the trajectories but in the surrounding cells with free bridge sites.

Polar scattering angle $\left(\theta_{\mathrm{v}}^{\prime}\right)$ distributions of reflected atoms are plotted in Fig. 5 for three initial collision energies $\left(\mathrm{E}_{\mathrm{col}}=0.2 \mathrm{eV}, 0.5 \mathrm{eV}\right.$ and $\left.1.2 \mathrm{eV}\right)$, two initial incident angles $\left(\theta_{\mathrm{v}}=0^{\circ}\right.$ and $\left.45^{\circ}\right)$ and different surface temperatures (i.e., without thermal bath, $100 \mathrm{~K}$ and $900 \mathrm{~K}$ ). These distributions can be compared with the collisions over a clean surface [46]. For normal incidence there is a clear shift of the peaks towards higher scattering angles (e.g., $\sim 60^{\circ}$ for $\mathrm{E}_{\mathrm{col}}=0.20 \mathrm{eV}$ ) while for off normal incidence this shift corresponds to smaller angles (e.g., $\sim 40^{\circ}$ for $\mathrm{E}_{\mathrm{col}}=0.20 \mathrm{eV}$ ), indicating clearly that the presence of preadsorbed oxygen atom affects these angular distributions. The analysis of initial position of the impinging atom for normal incidence regarding the final $\theta_{\mathrm{v}}{ }^{\prime}$ angle shows that atoms reflected at low angles are located initially far from the preadsorbed one while the high angles are mainly originated by atoms reflected close to the adatom. With the clean surface, the entrance barriers were quite similar over the main sites and therefore, the reflection on these barriers did not change a lot the initial incident angle [46]. Now, according to Fig. 2, the position of the barriers depends a lot of the impact parameter. Consequently, these barriers appear to be very corrugated with respect to the incoming atom leading to a broader angular distribution peaked around $60^{\circ}$. Obviously, this new PES topology is clearly created by the preadsorbed atom. Moreover, the higher is the initial $\mathrm{E}_{\mathrm{col}}$, the lower is this topological effect since the barriers can be overcome more easily.

Fig. 6 shows the final polar angle $\left(\theta_{\mathrm{v}}^{\prime}\right)$ distributions of $\mathrm{O}_{2}$ molecules formed via the ER reaction. 
Peaks appear at low angles $\left(10^{\circ}-20^{\circ}\right)$ for normal incidence and they are a bit shifted at larger ones $\left(15^{\circ}\right.$ $-40^{\circ}$ ) for off normal incidence. In general, the effect of surface temperature on the normal incidence distributions (Fig. 6, left panels) is small because the ER process occurs mainly via a direct mechanism and the interaction with the surface is negligible except for the preadsorbed atom that is thermalized with the surface. For off-normal incidence (Fig. 6, right panels) the interaction with the surface is higher and some distributions are double peaked. This fact shows the presence of a non-direct mechanism [67], more evident for lower collision energies at $T_{\text {surf }}=100 \mathrm{~K}$ (Fig. 6d) and practically insignificant when the surface temperature is increased (Fig. 6f). The analysis of trajectories shows that non-direct mechanism produces $\mathrm{O}_{2}$ molecules predominantly formed at low scattering angles $\left(10^{\circ}\right.$ $20^{\circ}$ ), whereas the direct mechanism drives to $\mathrm{O}_{2}$ in a wide range of scattering angles $\left(<45^{\circ}\right)$. Moreover, non-direct mechanism is mainly obtained for off-normal incidence whereas for normal one its contribution is practically constant $(<4 \%)$ at all the conditions explored. Concretely, for $\theta_{\mathrm{v}}=45^{\circ}$ and $\mathrm{E}_{\mathrm{col}}=0.2 \mathrm{eV}$, the non-direct formed $\mathrm{O}_{2}$ molecules account for $20 \%$ and $13 \%$ without thermal bath (Fig. 6b) and for a $T_{\text {surf }}=100 \mathrm{~K}$ (Fig. 6d), respectively. When $\mathrm{E}_{\text {col }}$ is increased to $1.0 \mathrm{eV}$ at $\mathrm{T}_{\text {surf }}=100$ $\mathrm{K}$, the non-direct mechanism becomes a bit less favourable (11\%), in agreement with a similar behaviour reported for $\mathrm{H}$ recombination over $\mathrm{Ni}(100)$ [67]. Obviously, in the present study, the incoming $\mathrm{O}$ atom samples initially only a $(1 \times 1)$ unit cell minimizing the possibility of the non-direct mechanism to occur. Thus, a deeper study is planned for sampling a bigger unit cell at several initial conditions.

The exchange of energy between the impinging atom and the preadsorbed surface (i.e., $\Delta \mathrm{E}_{\mathrm{col}}=\mathrm{E}_{\mathrm{col}}$ ' - $\left.E_{\text {col }}\right)$ was also evaluated at three selected collision energies $\left(E_{\text {col }}=0.2,0.5\right.$ and $\left.1.2 \mathrm{eV}\right)$ with $T_{\text {surf }}=$ $100 \mathrm{~K}$ and $900 \mathrm{~K}$ for normal incidence, and shown in Fig. 7. This energy exchange is in general negative (e.g., $<\Delta \mathrm{E}_{\mathrm{col}}>=-0.69 \mathrm{eV}$ for $\mathrm{E}_{\mathrm{col}}=1.2 \mathrm{eV}$ ), which means that the final collision energy of the 
reflected atom is lower than the initial one. The average energy exchange tends to diminish at higher temperatures although with rather broader distributions as could be expected. The behaviour is very similar as the one obtained for collisions over a clean surface [46].

An analysis of the internal states $\left(v^{\prime}, j^{\prime}\right)$ and the translational energy $\left(E_{c o l}{ }^{\prime}\right)$ of the formed molecules via ER reaction is presented in Fig. 8 at two initial collision energies $\left(E_{\mathrm{col}}=0.2\right.$ and $\left.1.2 \mathrm{eV}\right)$ for normal incidence. Only $\mathrm{T}_{\text {surf }}=500 \mathrm{~K}$ is considered as surface temperature effect was expected to be almost negligible. Molecules formed are translationally, vibrationally and rotationally excited. This amount of energy arises from the large exothermicity of ER process $\left(\Delta \mathrm{E}_{\mathrm{ER}}=-4.54 \mathrm{eV}\right.$ for $\mathrm{O}_{\text {(ad) }}$ initially over the bridge from the FPLEPS PES, Table III) and from the fact that the desorption process happens very quickly after the molecule formation. Consequently, energy exchange with the surface is limited and almost all the available energy goes to the molecule as usually observed in the ER recombination reaction. The effect of the value of $\mathrm{E}_{\mathrm{col}}$ is very small on these distributions (e.g., $<\mathrm{E}_{\mathrm{col}}{ }^{\prime}>=1.63$ and 1.60 $\mathrm{eV}$ for $\mathrm{E}_{\mathrm{col}}=0.2$ and $1.2 \mathrm{eV}$, respectively). The same trend is observed for the final internal energy $\left(<\mathrm{E}_{\text {int }}{ }^{\prime}>=2.54\right.$ and $2.46 \mathrm{eV}$ for $\mathrm{E}_{\mathrm{col}}=0.2$ and $1.2 \mathrm{eV}$, respectively $)$. Only a major rotational excitation is produced at higher $\mathrm{E}_{\mathrm{col}}$, due to the transfer of collision energy to the final molecular rotation.

\section{B. Quasithermal and hyperthermal conditions}

Reaction probabilities at quasithermal conditions $\left(\theta_{\mathrm{v}}, \mathrm{T}_{\text {surf }}=\mathrm{T}_{\mathrm{O}}=\mathrm{T}\right)$ for gas temperatures between $300 \mathrm{~K}$ and $1,500 \mathrm{~K}$ and for $\theta_{\mathrm{v}}=0^{\circ}$ and $45^{\circ}$, are presented in Fig. 9. The reflection of the impinging atom is the predominant process being the ER reaction the second one, with a probability of around $10 \%-30 \%$ at the studied temperatures. The rest of the processes are almost negligible, except the atomic reflection with the simultaneous desorption of the preadsorbed atom at high temperatures (i.e., 
$\mathrm{T}=1,500 \mathrm{~K}$ ). For off normal incidence, the ER probabilities (Fig. 9b) are even lower and hence the reflection probabilities become higher. This behaviour is consistent with the one found for low collision energies (Fig. 4), as $\mathrm{T}_{\text {surf }}$ had a small influence on reaction probabilities. The energy exchange with the surface was small $\left(<\Delta \mathrm{E}_{\mathrm{col}}>=-2.96 \times 10^{-3},-7.07 \times 10^{-3}\right.$ and $-7.94 \times 10^{-2} \mathrm{eV}$ for $\mathrm{T}_{\text {surf }}=300,900$ and $1,500 \mathrm{~K})$.

The $\mathrm{O}_{2}$ molecules formed via the ER reaction show angular distributions for normal and off normal atomic incidence with similar trends to those observed for state-specific conditions (Fig. 6). Their final energies (i.e., internal and translational) present similar values to those obtained for $E_{\text {col }}=0.2$ and 1.2 $\mathrm{eV}$ (Fig. 8). The mean values of these energies $\left(\left\langle\mathrm{E}_{\text {col }}{ }^{\prime}\right\rangle=1.28,1.52 \mathrm{eV}\right.$ and $\left\langle\mathrm{E}_{\text {int }}{ }^{\prime}\right\rangle=2.53,3.28 \mathrm{eV}$ at 300 and $1,500 \mathrm{~K}$, respectively) show that the increase of temperature enhances the total energy excitation of the molecule.

In order to study the possible coverage effect in the final polar angle distribution of reflected $\mathrm{O}$ atoms over HOPG in hyperthermal experiments [2] with $\mathrm{T}_{\text {surf }}=503 \mathrm{~K}$ and $\theta_{\mathrm{v}}=45^{\circ}$, we have calculated a large number of trajectories $(1,000,000)$ simulating exactly the experimental $\mathrm{O}$ velocity distribution, whose average translational energy corresponds to $5.2 \mathrm{eV}$. As HOPG surface consists of many orientations within the topmost layer, we have uniformly sampled the azimuthal velocity angle $\left(0^{\circ} \leq\right.$ $\left.\phi_{\mathrm{v}} \leq 360^{\circ}\right)$

The calculated distribution of reflected $\mathrm{O}$ atoms was split between in-plane and out-of-plane contributions (Fig. 10a), using an angular tolerance of $\pm 0.5^{\circ}$ for the in-plane distribution. The major part of the scattered O atoms were produced out-of-plane (99.6\%), hence the in-plane contribution is negligible in front of out-of-plane one to account for the total angular distribution. However, both are normalized to the unity in their maxima to enhance their comparison with experiments, which measured scattered atoms in the same plane as the initial plane formed by the normal to the surface and 
the $\mathrm{O}$ beam line. The QCT in-plane distribution shows a peak at low angles $\left(\sim 35^{\circ}\right)$ far from experiment $\left(\sim 62^{\circ}\right)$. This disagreement cannot be explained by the differences between in-plane and out-of-plane distributions. Nevertheless, the comparison of the QCT distribution for clean graphite matches nicely the experimental one [46], although the experimental HOPG surface coverage [2] is unknown. This seeming discrepancy could be explained by the fact that at hyperthermal conditions the atomic oxygen adsorption over a clean graphite surface is very low (0.15\%), as showed by our QCT prediction [46]. Therefore reflection would be mainly produced on an almost clean surface in spite of the large amount of incoming $\mathrm{O}$ atoms reaching the surface. Our previous microkinetic model confirmed as well a very low coverage at quasithermal conditions [5]. However, the present simulations are performed over an O-precovered surface (coverage close to $100 \%$ but only in the initially sampled $(1 \times 1)$ unit cell, allowing the atomic adsorption only in the empty neighboring cells), which shows a different behavior due to the influence of adatom. This coverage effect was partially observed in previous theoretical simulations of $\mathrm{O}$ impinging several models of graphene/graphite surfaces $[2,13]$. According to this, the coverage of HOPG samples during the experiment [2] should be small and the samples are expected to remain essentially clean after experimental $\mathrm{O} / \mathrm{O}_{2}$ mixture exposure. Other factors that could also affect the $\mathrm{O}$ scattering distribution would be the inclusion of the breaking of $\mathrm{C}$ sheet (i.e., vacants favor $\mathrm{O}$ adsorption) produced by the formation of $\mathrm{CO}$ and $\mathrm{CO}_{2}$ and its deformation during the total process, not included in the present study.

The $\mathrm{O}_{2}$ molecules formed via ER reaction have also been analysed showing an angular distribution (Fig. 10b) peaked at lower angles (peak at $\sim 40^{\circ}$ ) than reflected $\mathrm{O}$ atoms, close to the specular angle. There is as well some experimental data [2] on the $\mathrm{O}_{2}$ angular distribution (peaked around $60^{\circ}$ ), but as the initial hyperthermal flux was formed by both $\mathrm{O}_{2}$ and $\mathrm{O}\left(\mathrm{O}_{2}\right.$ with an average translational energy of $10.4 \mathrm{eV}$ ) these distributions are not directly comparable. The measured $\mathrm{O}_{2}$ distribution could have two 
possible contributions: a) $\mathrm{O}_{2}$ formed via ER reaction and b) initial $\mathrm{O}_{2}$ that is only scattered. In this same work [2] the authors conclude that the large value of the final $\mathrm{O}_{2} / \mathrm{O}$ intensity ratio with respect to the initial value in the beam $(\sim 0.48)$ should be originated by the new $\mathrm{O}_{2}$ molecules formed by the ER reaction. A comparison of direct measurements of the $\mathrm{O}_{2}$ molecules for experiments with both $\mathrm{O}_{2}$ and $\mathrm{O}_{2} / \mathrm{O}$ beams would allow a more truthful analysis of this point. The present calculations confirm the importance of ER reaction but its corresponding angular distribution differs from the experimental one. In order to make a more reliable comparison with experimental data [2], an extensive QCT study of $\mathrm{O}_{2}$ molecules impinging a clean surface is also in progress [68], which tends to produce angular distributions peaked at higher angles than those obtained for ER distributions, with a good agreement with the experiments.

The previous molecular dynamics simulations for hyperthermal collisions of atomic oxygen over some graphene models $[2,13]$ confirm that $\mathrm{O}_{2}$ is formed via a direct ER mechanism and that this process along with epoxide formation and inelastic atomic scattering are the main channels. These simulations do not control the surface temperature (e.g., this can increase up to 4,500K [13]) and only run 100 trajectories (i.e., large statistical errors) for normal incidence and $\mathrm{E}_{\mathrm{col}}=5 \mathrm{eV}$. Thus, a direct comparison with the present results is not accurate. However, a qualitatively comparison can be intended with respect to their models of graphene sheets functionalized with epoxides, which are closer to our model of unit cell, although their atomic coverages were also increased during the simulations. In general, it is observed that ER process is the most important one (e.g., $72 \%$ for model IV, $30 \%$ for model V [13] or $76-79 \%$ for model IV [2]) to be compared with $43,8 \%$, here calculated at the simulated experimental conditions. They also observed that $\mathrm{O}$ reflection was only observed for larger models (e.g., $17 \%$ for model V [13]) where sheet deformation was important. Our calculated value is around $31.9 \%$. The QCT larger values (e.g., comparing with model V) are consistent with the sampling of a $(1 \times 1)$ unit cell with an O-preadsorbed, which prevents a large adsorption, hence 
increasing the other channels, as ER or atomic reflection.

\section{Summary and conclusions}

A new PES for the interaction of atomic oxygen with an O-preadsorbed graphite (0001) surface has been constructed. The analytical FPLEPS PES is based on a set of 563 DFT data points calculated over high-symmetry sites centred in the ER channel. The symmetry of the graphite surface is fulfilled for the two-atom interaction by using appropriate periodic functions to describe the angular dependence and the X-Y dependence of the potential. The agreement between FPLEPS and DFT data is quite good, with a RMSD of $0.120 \mathrm{eV}$ for energies lower than $1 \mathrm{eV}$ over reactants.

The QCT method has been applied for the dynamics study of $\mathrm{O}$ collisions over O-preadsorbed graphite (0001) surface as a function of collision energy $(0.01-2.0 \mathrm{eV})$, surface temperature (100-

$1,500 \mathrm{~K})$ and incident angle $\left(0^{\circ}, 45^{\circ}\right)$. Moreover, quasithermal and hyperthermal conditions were also simulated and compared with available experimental data.

For normal incidence, ER reaction and $\mathrm{O}$ reflection are the main processes in agreement with earlier experimental and theoretical studies, becoming the ER more important than the $\mathrm{O}$ reflection for collision energies higher than $0.2 \mathrm{eV}$. For off normal incidence, ER recombination is always lower than O reflection. All other processes are almost negligible (e.g., atomic desorption) for both normal and off normal incidence.

Polar scattering angle distributions of atomic oxygen are shifted to higher angles compared to collisions with a clean surface for normal incidence, while for off normal incidence this shift corresponds to smaller angles, showing that preadsorbed oxygen affects these angular distributions.

Molecular oxygen formed via ER reaction is translationally and internally excited and presents polar 
scattering angle distributions centred at low angles, which are rather similar for all conditions studied.

The increase of surface temperature introduces small changes in almost all studied properties. Moreover, the study for reactants at quasithermal conditions is in agreement with the main features observed for studies at low initial collision energies.

Polar scattering angle distribution for $\mathrm{O}$ colliding with an O-preadsorbed surface at hyperthermal experimental conditions at $\theta_{\mathrm{v}}=45^{\circ}, \mathrm{T}_{\text {surf }}=503 \mathrm{~K}$ shows a peak at low angles $\left(\sim 35^{\circ}\right)$ far from experiment data $\left(\sim 62^{\circ}\right)$, but the calculated polar scattering angle distribution of atomic oxygen colliding onto a clean graphite surface matches well the experimental one. [46] However, the comparison between theoretical and experimental distributions cannot be straightforwardly done because the experimental HOPG surface coverage is unknown, and we show that coverage effect is significant. According to our results, we could conclude that the coverage for the HOPG samples during the experiment should be small, so they would remain essentially clean after the experimental conditions reported.

As possible improvements to the present study we would mention the possible inclusion of the breaking of $\mathrm{C}$ layer to produce $\mathrm{CO}, \mathrm{CO}_{2}$ and vacants and also the layer deformation during the total process.

\section{Acknowledgements}

This work was supported in part by the Spanish Ministry of Science and Innovation (Project CTQ2009-07647), by the Autonomous Government of Catalonia (Project 2009SGR1041) and by the European Commission research funding (Project FP7-SPACE-2009-242311). We thank to Dr. Jianming Zhang for providing us with the experimental initial velocity and translational energy 
distributions of atomic and molecular oxygen in the experiments for hyperthermal $\mathrm{O}\left({ }^{3} \mathrm{P}\right) / \mathrm{O}_{2}$ colliding over HOPG. We are also grateful to Dr. Fabio Busnengo for sending us the GLO subroutines and for useful discussions about this method. 


\section{TABLES}

Table I. Optimal parameters at several $\phi$ angles for the preadsorbed $\mathrm{O}$ atom onto $\mathrm{B} 1$ site.

\begin{tabular}{|l|c|cccc|}
\hline \multicolumn{2}{|c|}{ Parameters } & \multicolumn{4}{|c|}{$\phi /{ }^{\circ}$} \\
\cline { 3 - 6 } \multicolumn{2}{|c|}{} & 0 & 30 & 60 & 90 \\
\hline$\Delta_{\mathrm{AB}} /$ adim & $\mathrm{P}_{1}$ & -0.100 & 0.010 & -0.270 & 0.010 \\
$\Delta_{\mathrm{As}, \mathrm{Bs}} / \operatorname{adim}$ & $\mathrm{P}_{2}$ & -0.130 & -0.160 & -0.130 & -0.350 \\
$\mathrm{~A}_{1} / \mathrm{eV}$ & $\mathrm{P}_{3}$ & -1.970 & -0.800 & -0.410 & 2.240 \\
$\mathrm{~b}_{1} / \AA$ & $\mathrm{P}_{4}$ & 1.070 & 1.050 & 1.110 & 1.530 \\
$\sigma_{1} / \AA^{2}$ & $\mathrm{P}_{5}$ & 0.170 & 0.080 & 0.170 & 0.200 \\
$\mathrm{Z}_{\mathrm{cm}, 1} / \AA$ & $\mathrm{P}_{6}$ & 1.720 & 1.730 & 1.980 & 1.270 \\
$\sigma_{\mathrm{cm}, 1} / \AA^{2}$ & $\mathrm{P}_{7}$ & 0.060 & 0.020 & 0.090 & 0.130 \\
$\mathrm{~A}_{2} / \mathrm{eV}$ & $\mathrm{P}_{8}$ & 0.850 & 1.330 & 0.920 & 0.380 \\
$\mathrm{~b}_{2} / \AA$ & $\mathrm{P}_{9}$ & 2.260 & 1.640 & 1.690 & 2.950 \\
$\sigma_{2} / \AA^{2}$ & $\mathrm{P}_{10}$ & 0.220 & 0.090 & 0.130 & 0.500 \\
$\mathrm{Z}_{\mathrm{cm}, 2} / \AA$ & $\mathrm{P}_{11}$ & 1.390 & 1.430 & 1.360 & 1.260 \\
$\sigma_{\mathrm{cm}, 2} / \AA \AA^{2}$ & $\mathrm{P}_{12}$ & 0.060 & 0.020 & 0.020 & 0.040 \\
\hline
\end{tabular}


Table II. Coefficients $\left(\mathrm{B}_{\mathrm{ji}}\right)$ for each of the $\mathrm{P}_{\mathrm{j}}(\phi)$ parameters for the preadsorbed $\mathrm{O}$ atom onto $\mathrm{B} 1$ site $^{\mathrm{a}}$

\begin{tabular}{|l|cccc|}
\hline Parameters & $\mathrm{i}=0$ & $\mathrm{i}=1$ & $\mathrm{i}=2$ & $\mathrm{i}=3$ \\
\hline $\mathrm{B}_{1 \mathrm{i}} /$ adim & -0.102 & $5.67 \times 10^{-2}$ & $5.67 \times 10^{-2}$ & -0.112 \\
$\mathrm{~B}_{2 \mathrm{i}} /$ adim & -0.177 & $6.33 \times 10^{-2}$ & $-6.33 \times 10^{-2}$ & $4.67 \times 10^{-2}$ \\
$\mathrm{~B}_{3 \mathrm{i}} / \mathrm{eV}$ & -0.358 & -1.533 & 0.493 & -0.572 \\
$\mathrm{~B}_{4 \mathrm{i}} / \AA$ & 1.153 & -0.173 & 0.147 & $-5.67 \times 10^{-2}$ \\
$\mathrm{~B}_{5 \mathrm{i}} / \AA^{2}$ & 0.145 & $-4.00 \times 10^{-2}$ & $4.00 \times 10^{-2}$ & $2.50 \times 10^{-2}$ \\
$\mathrm{~B}_{6 \mathrm{i}} / \AA$ & 1.735 & $6.67 \times 10^{-2}$ & -0.240 & 0.158 \\
$\mathrm{~B}_{7 \mathrm{i}} / \AA^{2}$ & $6.83 \times 10^{-2}$ & $-4.67 \times 10^{-2}$ & $2.67 \times 10^{-2}$ & $1.17 \times 10^{-2}$ \\
$\mathrm{~B}_{8 \mathrm{i}} / \mathrm{eV}$ & 0.955 & 0.293 & -0.340 & $-5.83 \times 10^{-2}$ \\
$\mathrm{~B}_{9 \mathrm{i}} / \AA$ & 1.978 & -0.247 & 0.627 & $-9.83 \times 10^{-2}$ \\
$\mathrm{~B}_{10 \mathrm{i}} / \AA^{2}$ & 0.193 & -0.107 & 0.167 & $-3.33 \times 10^{-2}$ \\
$\mathrm{~B}_{11 \mathrm{i}} / \AA$ & 1.372 & $6.67 \times 10^{-2}$ & $-4.67 \times 10^{-2}$ & $-1.67 \times 10^{-3}$ \\
$\mathrm{~B}_{12 \mathrm{i}} / \AA^{2}$ & $3.00 \times 10^{-2}$ & $6.67 \times 10^{-3}$ & $2.00 \times 10^{-2}$ & $3.33 \times 10^{-3}$ \\
\hline
\end{tabular}

${ }^{\text {a} A c c o r d i n g ~ t o ~ e q u a t i o n ~(7) . ~}$ 
Table III. Asymptotic energy values in the FPLEPS PES

\begin{tabular}{|c|c|}
\hline asymptote & $\mathrm{E} / \mathrm{eV}$ \\
\hline $\mathrm{O}_{(\mathrm{g})}+\mathrm{O}_{(\mathrm{g})}+$ graphite & 0.00 \\
$\mathrm{O}_{(\mathrm{ad})}($ on bridge site $)+\mathrm{O}_{(\mathrm{g})}$ & -0.68 \\
$\mathrm{O}_{2(\mathrm{~g})}+$ graphite & -5.22 \\
\hline
\end{tabular}




\section{FIGURE CAPTIONS}

Figure 1 a) Coordinates system for one incoming atom interacting with an adatom over graphite (0001) surface. Internal $(\mathrm{R}, \theta, \phi)$ and centre of mass coordinates can be used instead of Cartesian coordinates.

The initial impact parameter (b) for normal incidence is also shown. b) Top view of the $(1 \times 1)$ unit cell (lattice parameter $\mathrm{a}=\mathrm{b}=2.468 \AA$ ) along with the crystal (u,v) and the orthogonal axes $(\mathrm{X}, \mathrm{Y})$. The twelve used sites (black and white squares) for describing well the two atom symmetry of the cell are indicated; their $(X, Y)$ coordinates are: $\left(0, \frac{a \sqrt{3}}{6}\right),\left(\frac{3 a}{4}, \frac{5 a \sqrt{3}}{12}\right),\left(\frac{5 a}{4}, \frac{5 a \sqrt{3}}{12}\right),\left(0, \frac{a \sqrt{3}}{3}\right),(0,0)$, $\left(\frac{a}{2}, \frac{a \sqrt{3}}{6}\right),\left(\frac{a}{4}, \frac{a \sqrt{3}}{4}\right),\left(\frac{3 a}{4}, \frac{a \sqrt{3}}{4}\right),\left(\frac{a}{2}, 0\right),\left(\frac{3 a}{4}, \frac{a \sqrt{3}}{12}\right),\left(\frac{a}{4}, \frac{a \sqrt{3}}{12}\right),\left(\frac{a}{2}, \frac{a \sqrt{3}}{3}\right)$ for B1, B2, B3, T1, T2, H, $\mathrm{T} 1 \mathrm{H} 1, \mathrm{~T} 1 \mathrm{H} 2, \mathrm{~T} 1 \mathrm{H} 3, \mathrm{~T} 2 \mathrm{H} 1, \mathrm{~T} 2 \mathrm{H} 2, \mathrm{~T} 2 \mathrm{H} 3$, respectively. The minimum triangle shaded was used for the atomic interaction with the clean surface [46]. Two layers of graphite are depicted: black circles (1st layer) and gray circles (2nd layer).

Figure 2 DFT (right panels) and FPLEPS (left panels) equipotential energy contour plots for different $\phi$ angles of incoming atom $\mathrm{B}$ when the preadsorbed atom $\mathrm{A}$ is located on $\mathrm{B} 1$ site with $\mathrm{Z}_{\mathrm{A}}=1.384 \AA$, varying the $Z_{\mathrm{B}}$ distance to the surface and the impact parameter between the two atoms. The contour plots are depicted in increments of $0.25 \mathrm{eV}$, and the zero of energy is taken as $\left[\mathrm{O}_{\mathrm{A},(\mathrm{ad})}+\mathrm{O}_{\mathrm{B},(\mathrm{g})}\right]$. The value of $0.5(a, b)$ and $0 \mathrm{eV}$ (others) of energy corresponds to the nearest solid line.

Figure 3 Energy contour plots for fixed preadsorbed $A$ atom (white circle) at $Z_{\mathrm{A}}=1.384 \AA$ on a $\mathrm{B} 1$ (a, d), $\mathrm{B} 2$ (b) and $\mathrm{B} 3$ (c) site for a grid $\left(\mathrm{X}_{\mathrm{B}}, \mathrm{Y}_{\mathrm{B}}\right)$ of the incoming $\mathrm{B}$ atom at $\left.\mathrm{Z}_{\mathrm{B}}=3.00 \AA \mathrm{a}, \mathrm{a}, \mathrm{c}\right)$ and $\mathrm{Z}_{\mathrm{B}}=$ $1.384 \AA$ (d). The contour plots are depicted in increments of $0.20 \mathrm{eV}$ for a, b and c, and $0.4 \mathrm{eV}$ for $\mathrm{d}$. 


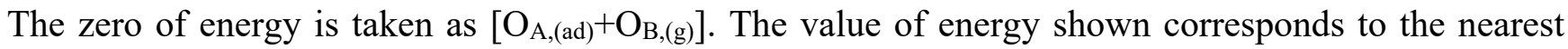
solid line, otherwise indicated.

Figure 4 QCT reaction probabilities for an O-precovered surface as a function of O collision energy at initial $\theta_{\mathrm{v}}=0^{\circ}$ (left panels) and $\theta_{\mathrm{v}}=45^{\circ}$ (right panels) without thermal bath (a, b) and considering two surface temperatures $\left(\mathrm{T}_{\text {surf }}=100 \mathrm{~K}(\mathrm{c}, \mathrm{d})\right.$ and $\left.900 \mathrm{~K}(\mathrm{e}, \mathrm{f})\right)$. Channels are labelled as: $\mathrm{O}$ reflection (open squares), ER (filled squares), $\mathrm{O}$ adsorption (filled circles), $\mathrm{O}$ adsorption $+\mathrm{O}$ desorption (open circles) and $\mathrm{O}$ desorption (open triangles).

Figure 5 QCT polar scattering angle $\left(\theta_{\mathrm{v}}^{\prime}\right)$ distributions of the reflected atoms at $\theta_{\mathrm{v}}=0^{\circ}$ (left panels) and $45^{\circ}$ (right panels) without thermal bath $(\mathrm{a}, \mathrm{b})$ and considering two surface temperatures $\left(\mathrm{T}_{\text {surf }}=100 \mathrm{~K}\right.$ (c, d) and $900 \mathrm{~K}(\mathrm{e}, \mathrm{f})$ ) for several initial collision energies $\left(\mathrm{E}_{\mathrm{col}}=0.2,0.5\right.$ and $1.2 \mathrm{eV}$ using solid, dashed and dotted lines, respectively). The distributions are normalized to unit area.

Figure 6 QCT polar scattering angle $\left(\theta_{\mathrm{v}}{ }^{\prime}\right)$ distributions of the reflected $\mathrm{O}_{2}$ molecules formed by ER reaction at $\theta_{\mathrm{v}}=0^{\circ}$ (left panels) and $45^{\circ}$ (right panels) without thermal bath (a, b) and considering two surface temperatures $\left(\mathrm{T}_{\text {surf }}=100 \mathrm{~K}(\mathrm{c}, \mathrm{d})\right.$ and $\left.900 \mathrm{~K}(\mathrm{e}, \mathrm{f})\right)$ for several initial collision energies $\left(\mathrm{E}_{\mathrm{col}}=\right.$ 0.2, 0.5 and $1.2 \mathrm{eV}$ using solid, dashed and dotted lines, respectively). The distributions are normalized to unit area.

Figure 7 QCT energy exchange $\left(\Delta \mathrm{E}_{\mathrm{col}}\right)$ for reflected atoms at initial $\mathrm{E}_{\mathrm{col}}=0.2,0.5$ and $1.2 \mathrm{eV}$ for an oxygen preadsorbed surface (solid, dashed and dotted lines, respectively) at: a) $\mathrm{T}_{\text {surf }}=100 \mathrm{~K}$ and $\mathrm{b}$ ) $\mathrm{T}_{\text {surf }}=900 \mathrm{~K}$ for normal incidence. Mean values for $\Delta \mathrm{E}_{\mathrm{col}}$ are reported between parentheses. 
Figure 8 Final collision energies (a), vibrational levels (b) and rotational levels at v'= 5 (c) of $\mathrm{O}_{2}$ molecules formed via $\mathrm{ER}$ at $\mathrm{T}_{\text {surf }}=500 \mathrm{~K}$ under normal incidence, for $\mathrm{E}_{\mathrm{col}}=0.2 \mathrm{eV}$ (solid line) and 1.2 $\mathrm{eV}$ (dashed line).

Figure 9 QCT reaction probabilities for the incoming $\mathrm{O}$ atom interacting with an O-precovered surface at different temperatures $\left(\mathrm{T}=\mathrm{T}_{\mathrm{O}}=\mathrm{T}_{\text {surf }}\right.$ ) for initial $\theta_{\mathrm{v}}=0^{\circ}(\mathrm{a})$ and $\theta_{\mathrm{v}}=45^{\circ}(\mathrm{b})$; $\mathrm{O}$ reflection (open squares), ER (filled squares) and O desorption (open triangles).

Figure 10 Polar scattering angle $\left(\theta_{\mathrm{v}}{ }^{\prime}\right)$ distributions of the reflected $\mathrm{O}$ atoms (a) and the $\mathrm{O}_{2}$ molecules formed via ER reaction (b) for initial experimental hyperthermal conditions, i.e., with $\theta_{\mathrm{v}}=45^{\circ}, \mathrm{T}_{\text {surf }}=$ $503 \mathrm{~K}$ and $<\mathrm{E}_{\mathrm{col}}>=5.2 \mathrm{eV}$. The experimental curve (solid line [2]) is compared with the calculated inplane distribution (dashed line) and with the out-of-plane distribution (dotted line). 
Figure 1

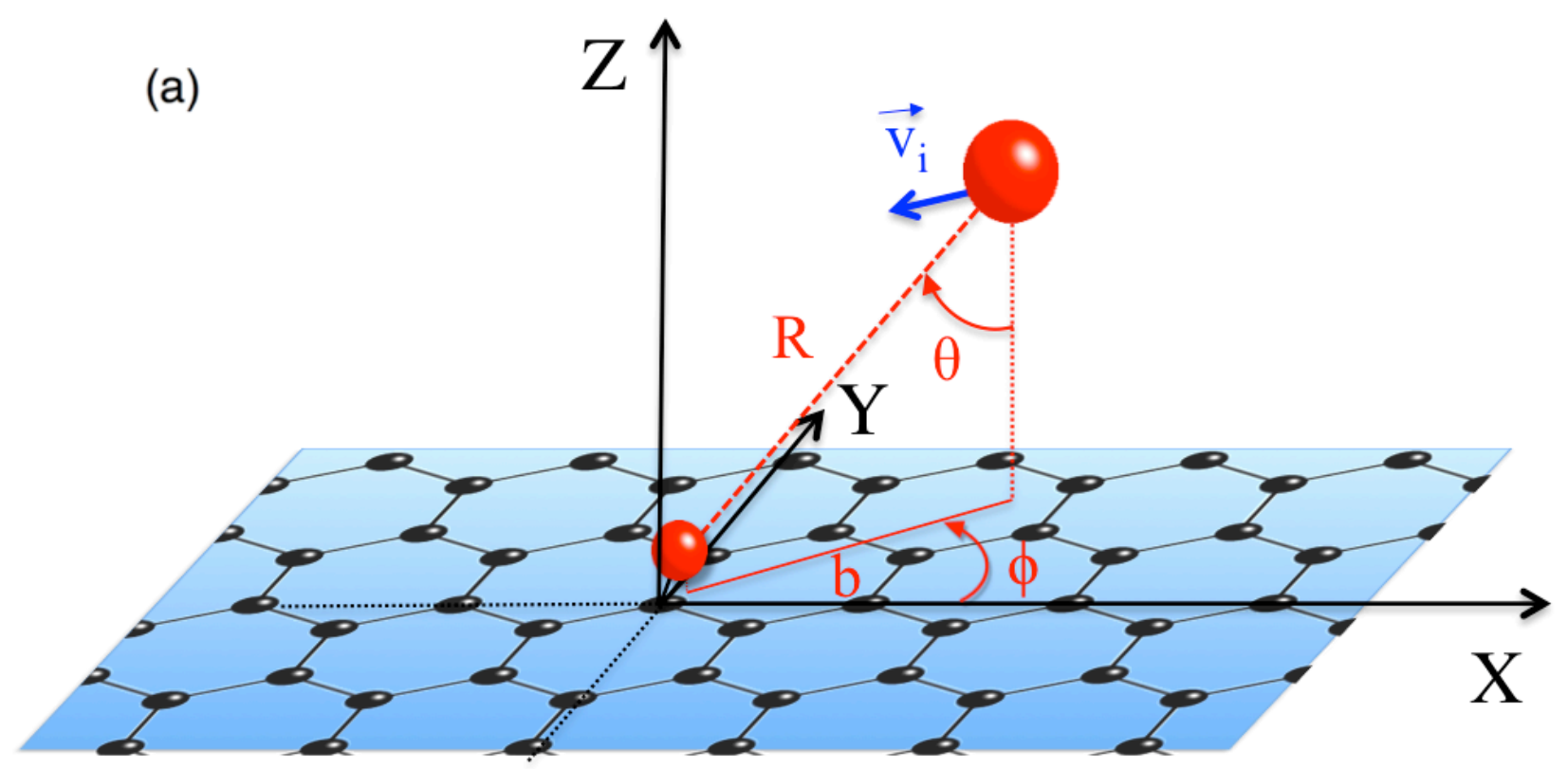

(b)

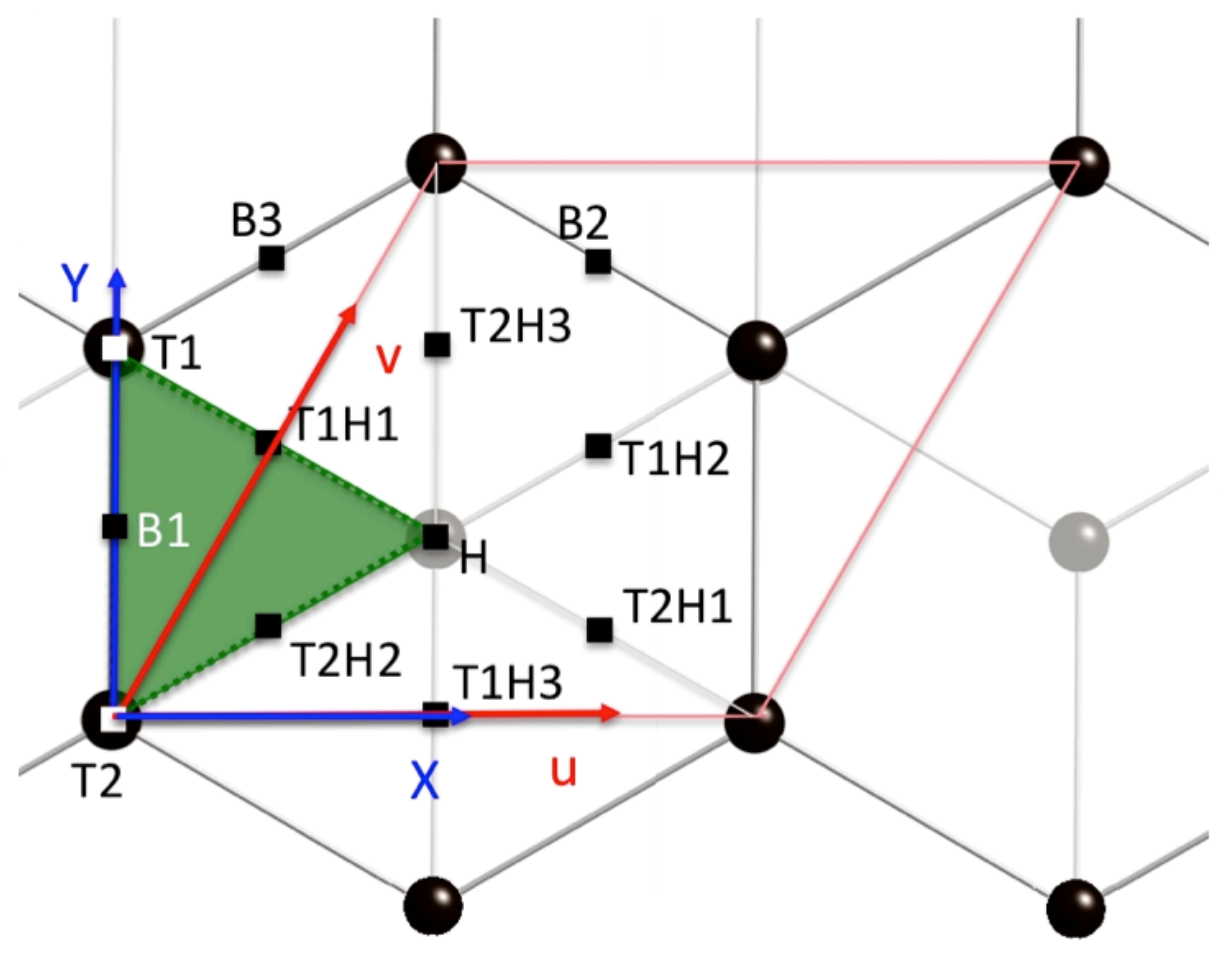


Figure 2

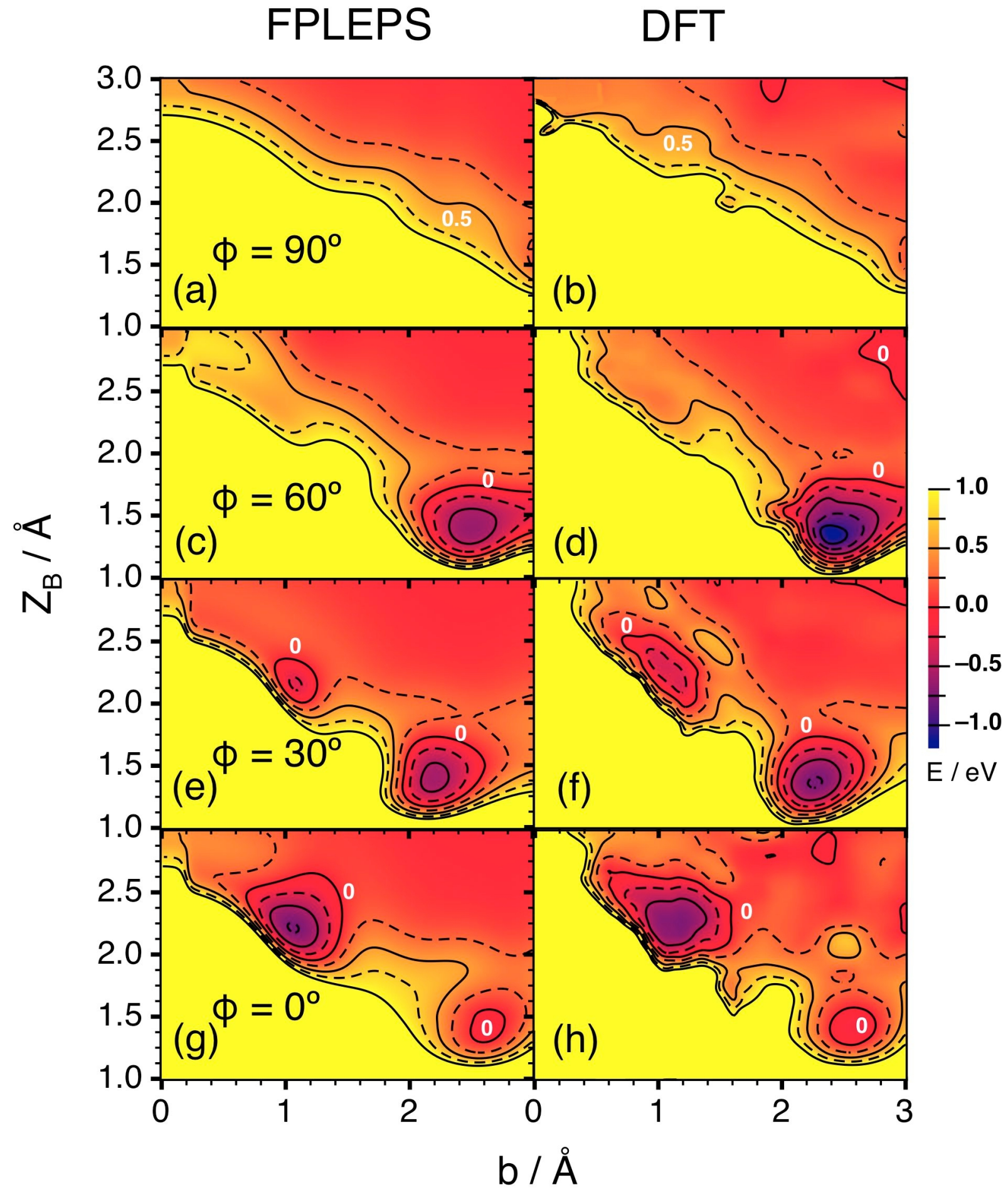


Figure 3

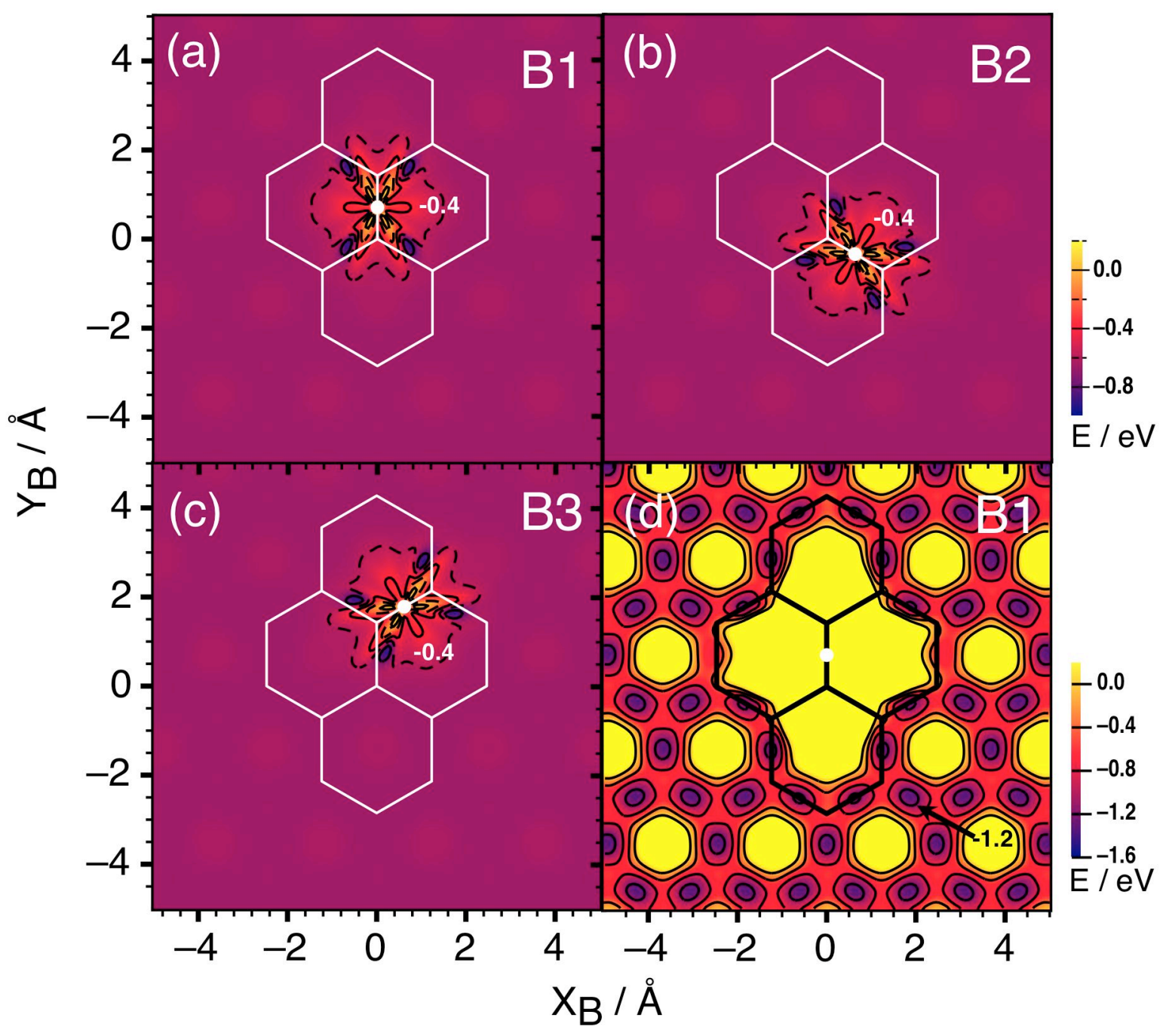


Figure 4

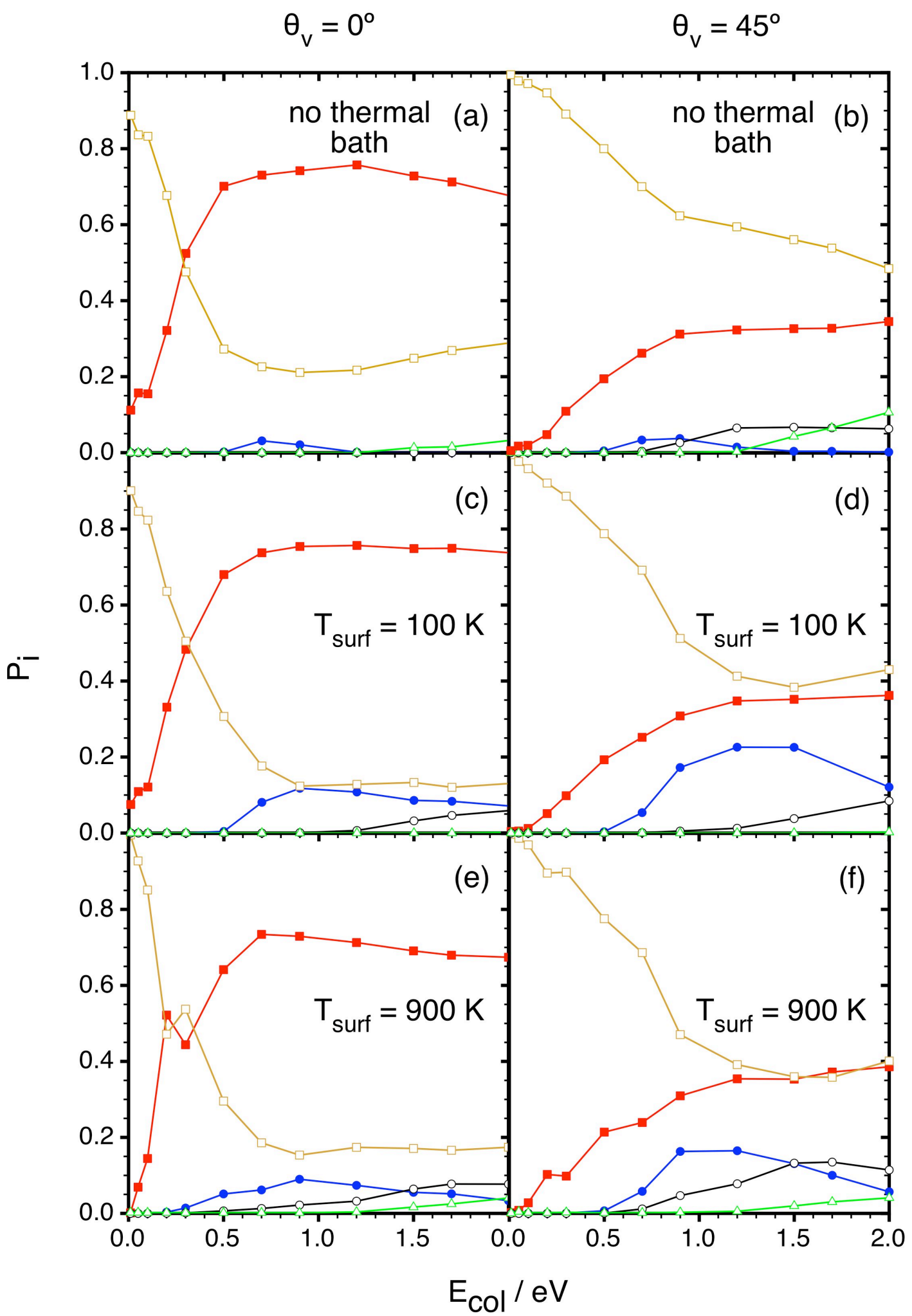


Figure 5

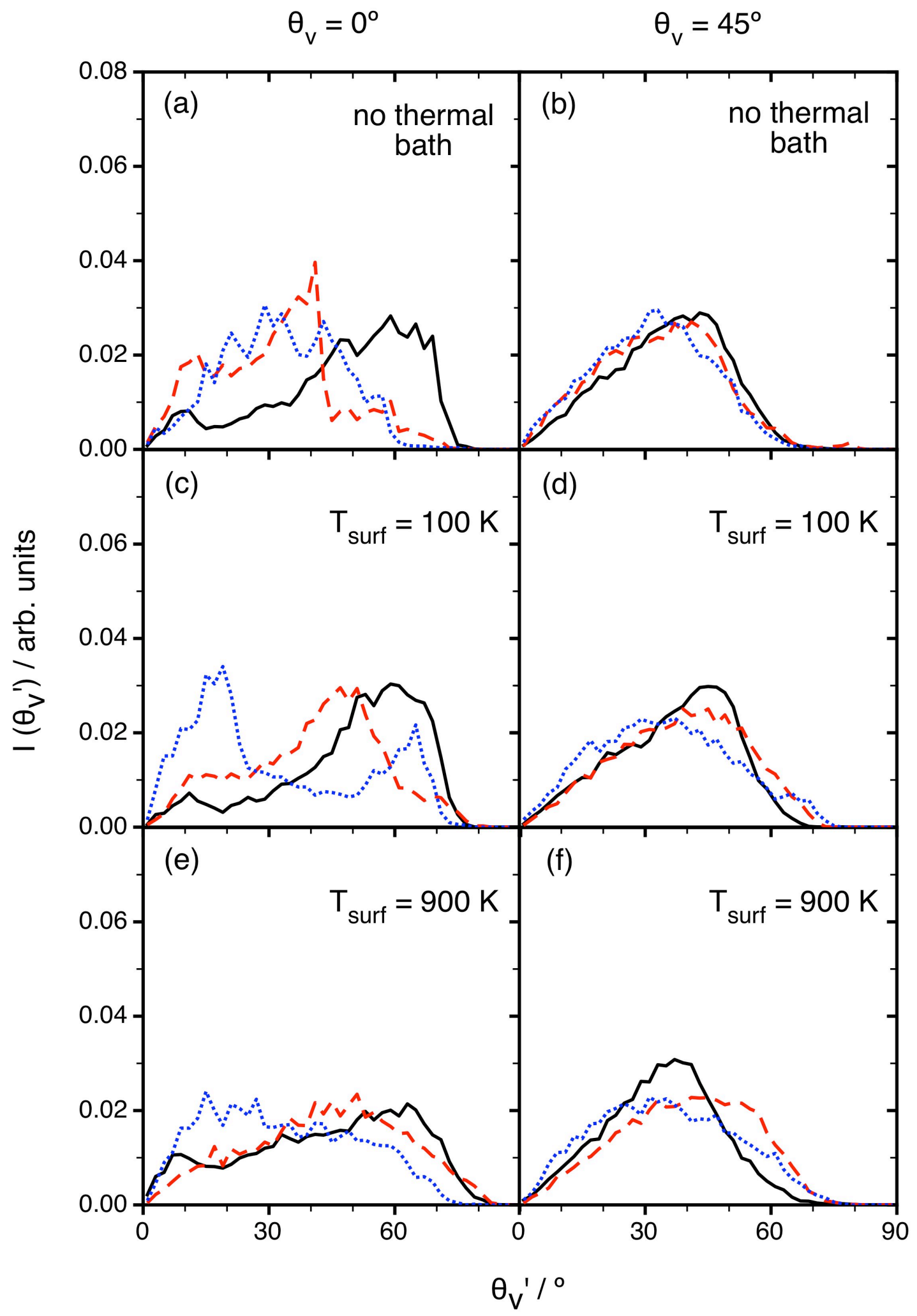


Figure 6

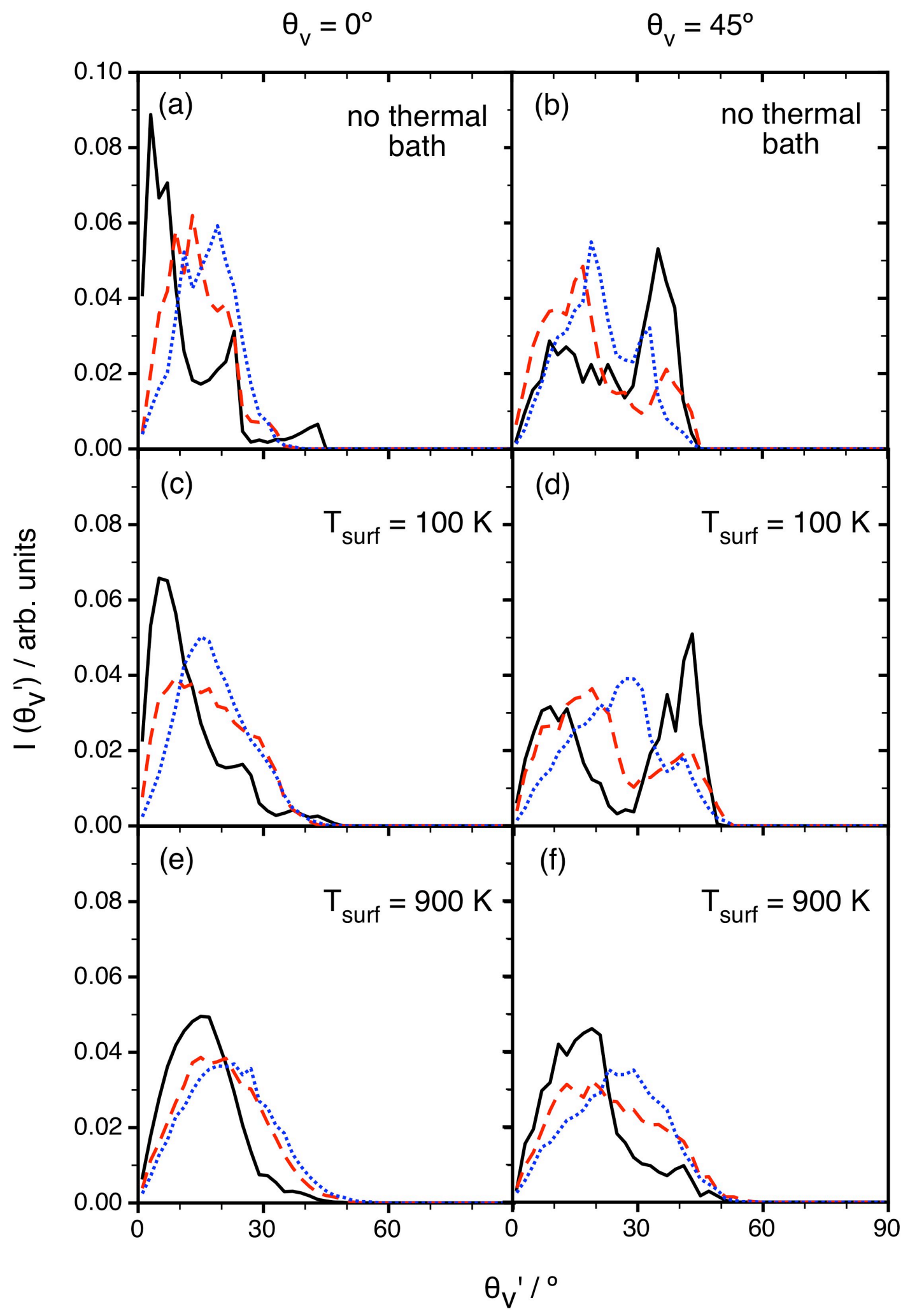


Figure 7

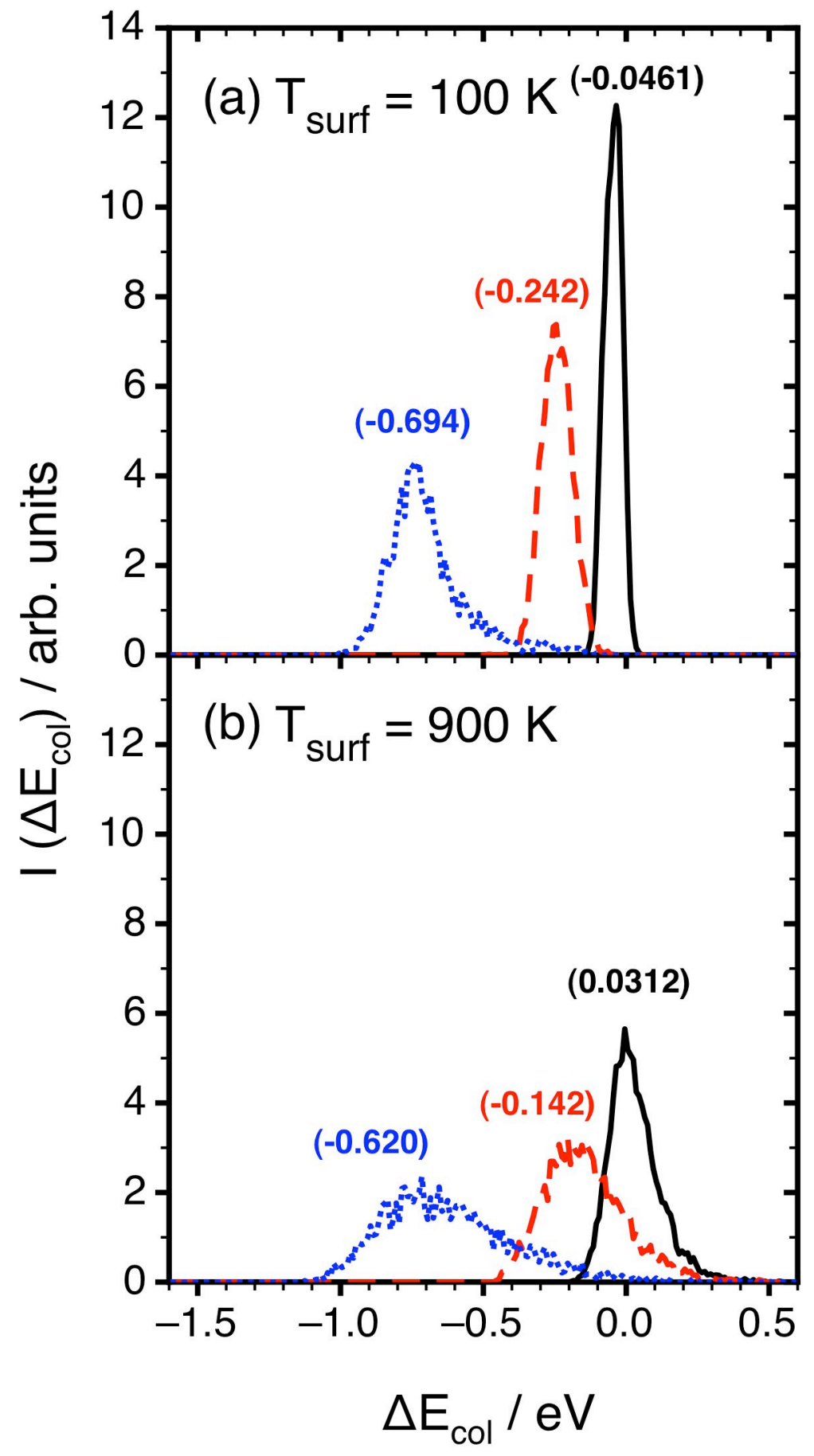


Figure 8
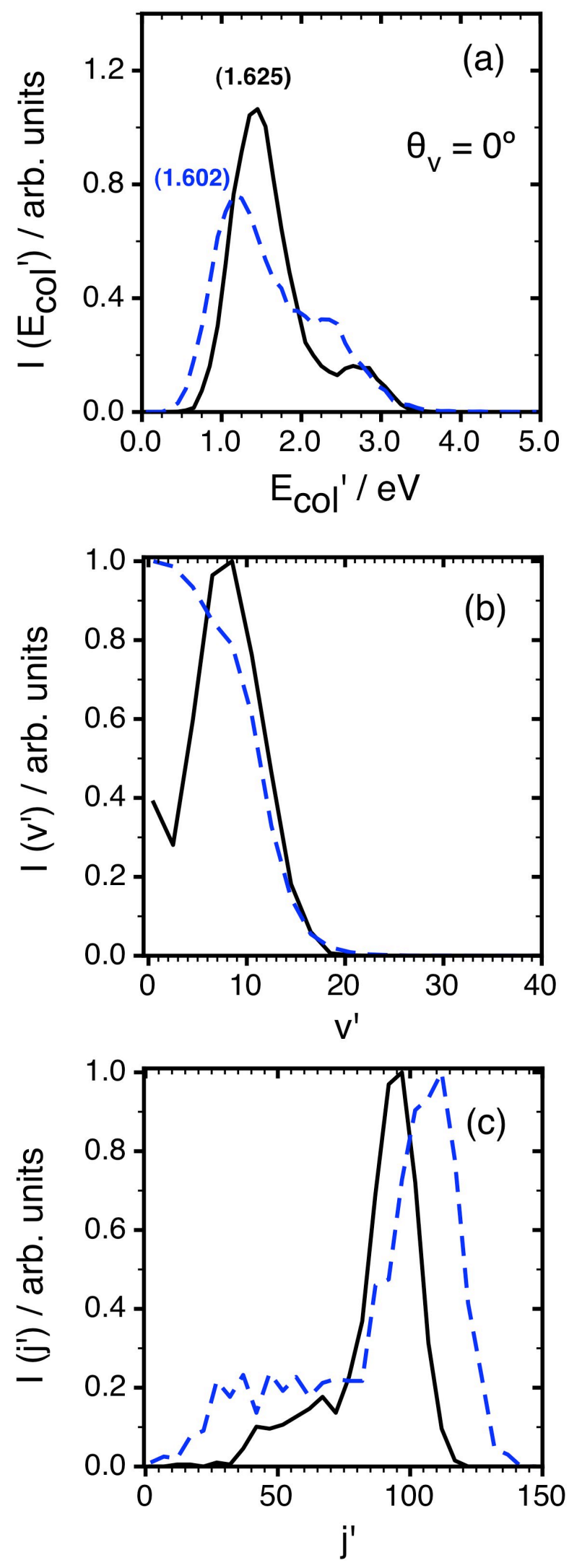
Figure 9

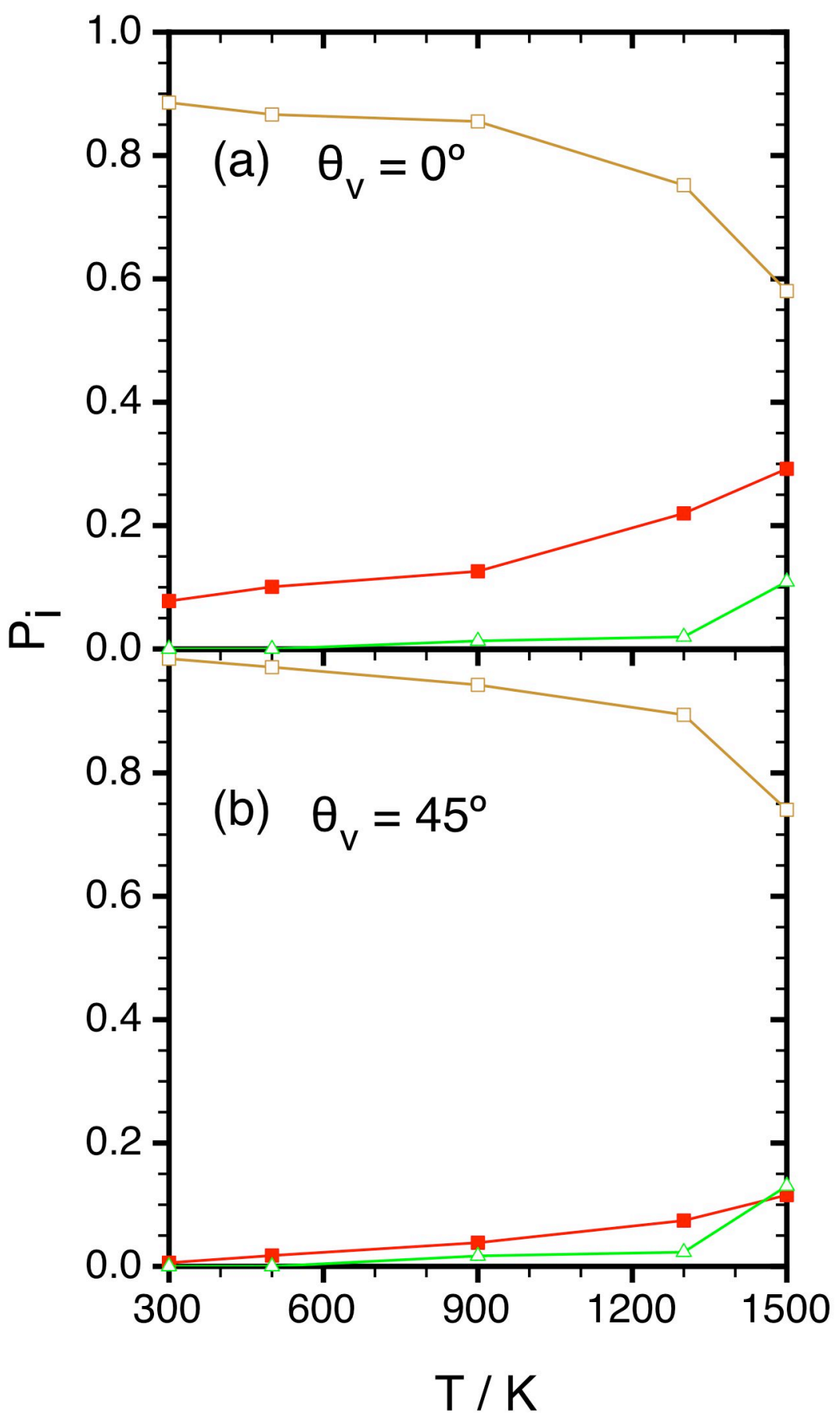


Figure 10
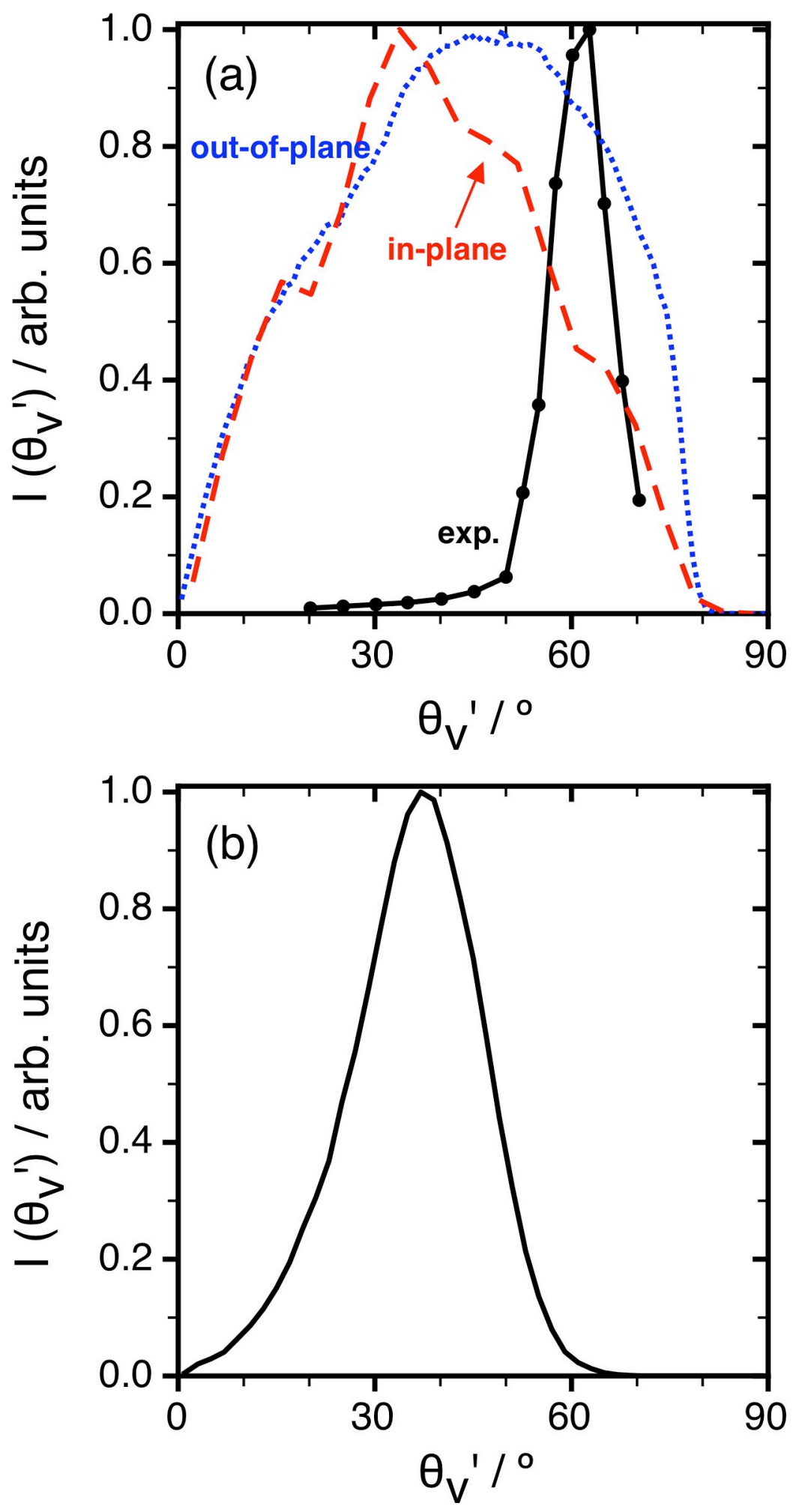
Supporting Information Available: Complete reference [55] is Gaussian 09, Revision A.1, M. J. Frisch, G. W. Trucks, H. B. Schlegel, G. E. Scuseria, M. A. Robb, J. R. Cheeseman, G. Scalmani, V. Barone, B. Mennucci, G. A. Petersson, H. Nakatsuji, M. Caricato, X. Li, H. P. Hratchian, A. F. Izmaylov, J. Bloino, G. Zheng, J. L. Sonnenberg, M. Hada, M. Ehara, K. Toyota, R. Fukuda, J. Hasegawa, M. Ishida, T. Nakajima, Y. Honda, O. Kitao, H. Nakai, T. Vreven, J. A. Montgomery, Jr., J. E. Peralta, F. Ogliaro, M. Bearpark, J. J. Heyd, E. Brothers, K. N. Kudin, V. N. Staroverov, R. Kobayashi, J. Normand, K. Raghavachari, A. Rendell, J. C. Burant, S. S. Iyengar, J. Tomasi, M. Cossi, N. Rega, J. M. Millam, M. Klene, J. E. Knox, J. B. Cross, V. Bakken, C. Adamo, J. Jaramillo, R. Gomperts, R. E. Stratmann, O. Yazyev, A. J. Austin, R. Cammi, C. Pomelli, J. W. Ochterski, R. L. Martin, K. Morokuma, V. G. Zakrzewski, G. A. Voth, P. Salvador, J. J. Dannenberg, S. Dapprich, A. D. Daniels, Ö. Farkas, J. B. Foresman, J. V. Ortiz, J. Cioslowski, and D. J. Fox, Gaussian, Inc., Wallingford CT, 2009. 
Table of Contents (TOC) Image

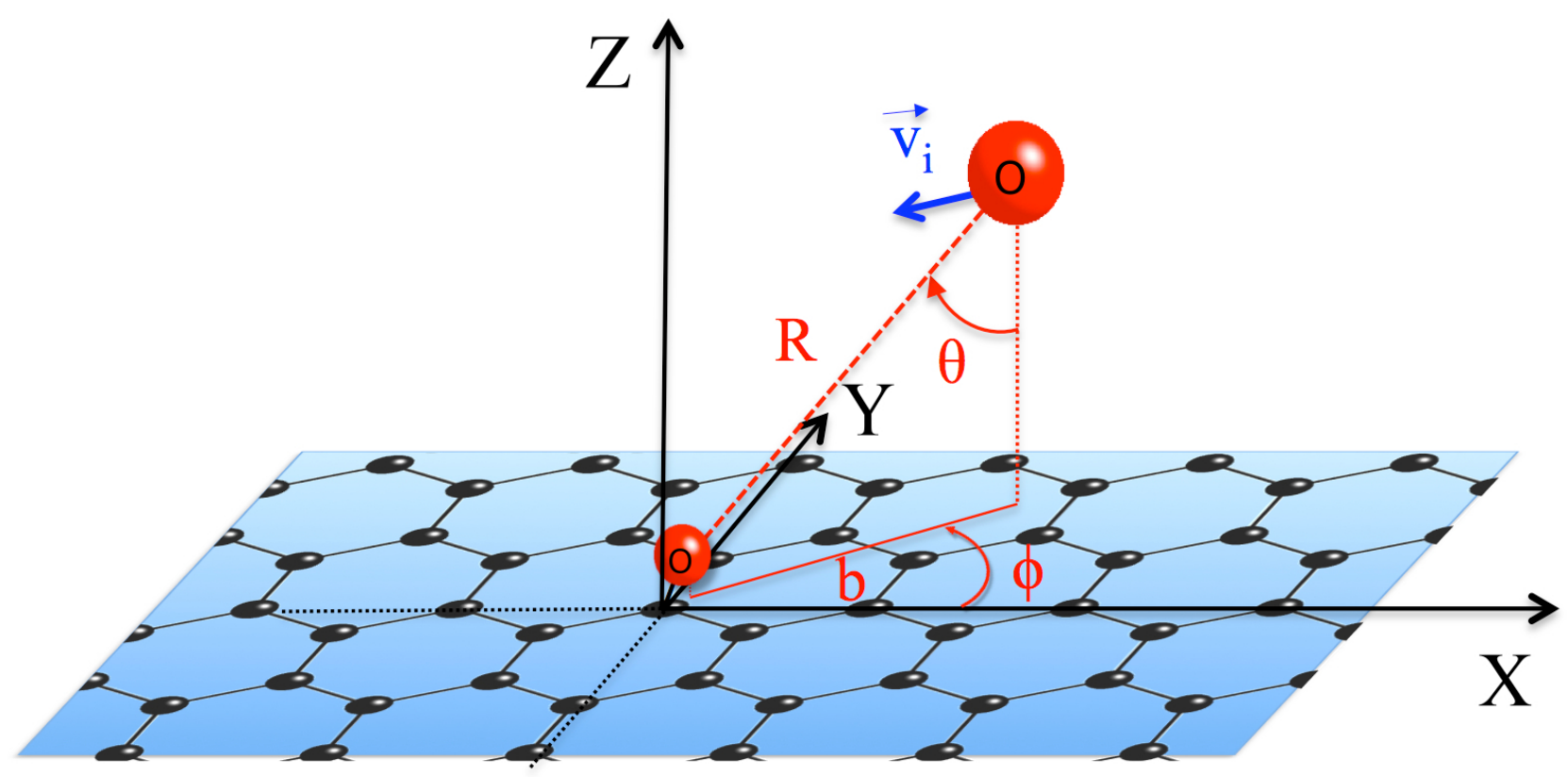




\section{References}

[1] Ngo, T.; Snyder, E. J.; Tong, W. M.; Williams, R. S.; Anderson, M. S. Surf. Sci. Lett. 1994, 314, L817-L822.

[2] Paci, J. T.; Upadhyaya, H. P.; Zhang, J.; Schatz, G. C.; Minton, T. K. J. Phys. Chem. A 2009, 113, 4677-4685.

[3] Nicholson, K. T.; Minton, T. K.; Sibener, S. J. J. Phys. Chem. B 2005, 109, 8476-8480.

[4] Kinoshita, H.; Umeno, M.; Tagawa, M.; Ohmae, N. Surf. Sci. 1999, 440, 49-59.

[5] Morón, V.; Gamallo, P.; Sayós, R. Theor. Chem. Acc. 2011, 128, 683-694.

[6] Lamoen, D.; Persson, B. N. J. J. Chem. Phys. 1998, 108, 3332-3341.

[7] Sorescu, D.; Jordan, K. D.; Avouris, P. J. Phys. Chem. B 2001, 105, 11227-11232.

[8] Incze, A.; Pasturel, A.; Chatillon, C. Appl. Surf. Sci. 2001, 177, 226-229.

[9] Incze, A.; Pasturel, A.; Chatillon, C. Surf. Sci. 2003, 537, 55-63.

[10] Xu, Y.; Li, J. Chem. Phys. Lett. 2004, 400, 406-412.

[11] Ito, J.; Nakamura, J.; Natori, A. J. App. Phys. 2008, 103, 113712-1-5.

[12] Xu, Z.; Xue, K. Nanotech. 2010, 21, 045704-1-7.

[13] Srinivasan, S. G.; van Duin, A. C. T. J. Phys. Chem. A 2011, 115, 13269-13280.

[14] Xu, S. C.; Chen, H-L.; Lin, M. C. J. Phys. Chem. C 2012, 116, 1841-1849.

[15] Zhu, X. Y.; Lee, S. M.; Lee, Y. H.; Frauenheim, T. Phys. Rev. Lett. 2000, 85, 2757-2760.

[16] Walch, S. P. Chem. Phys. Lett. 2003, 374, 501-505.

[17] Cohen, L. K. J. Chem. Phys. 1993, 99, 9652-9663.

[18] McCreery, J. H.; Wolken, G. J. Chem. Phys. 1975, 63, 2340-2349.

[19] Wolken, G. J. Chem. Phys. 1978, 68, 4338-4342.

[20] McCreery, J. H.; Markworth, A. J.; McCoy, J. K. Scr. Metall. 1988, 22, 1557-1562.

[21] Avdeev, V. I.; Upton, T. H.; Weinberg, W. H.; Goddard, W. A. Surf. Sci. 1980, 95, 391-402.

[22] Mowrey, R. C. J. Chem. Phys. 1993, 99, 7049-7055.

[23] Böyükata, M.; Güvenç, Z. B. Surf. Sci. 2004, 562, 183-194.

[24] Sheng, J.; Zhang, J. Z. H. J. Chem. Phys., 1993, 99, 1373-1381.

[25] Dai, J.; Sheng, J.; Zhang, J. Z. H. J. Chem. Phys. 1994, 101, 1555-1563.

[26] Dai, J.; Zhang, J. Z. H. J. Chem. Phys. 1995, 102, 6280-6289. 
[27] Forni, A.; Wiesenekker, G.; Baerends, E. J.; Tantardini, G. F. J. Phys.: Condens. Matter, 1995, 7, 7195-7207.

[28] Kara, A.; DePristo, A. E. J. Chem. Phys. 1988, 88, 2033-2035.

[29] Khanra, B. C.; Saha, S. K. Chem. Phys. Lett. 1983, 95, 217-220.

[30] Diao, Z. Y.; Han, L. L.; Wang, Z. X.; Dong, C. C. J. Phys. Chem. B 2005, 109, 5739-5745.

[31] Persson, M.; Jackson, B. J. Chem. Phys. 1994, 102, 1078-1093.

[32] Caratzoulas, S.; Jackson, B.; Persson, M. J. Chem. Phys. 1997, 107, 6420-6431.

[33] Shalashilin, D. V.; Jackson, B.; Persson, M. Faraday Discuss. 1998, 110, 287-300.

[34] Persson, M.; Strömquist, J.; Bengtsson, L.; Jackson, B.; Shalashilin, D. V.; Hammer, B. J. Chem. Phys. 1999, 110, 2240-2249.

[35] Kratzer, P. Chem. Phys. Lett. 1998, 288, 396-402.

[36] Meijer, A. J. H. M.; Farebrother, A. J.; Clary, D. C.; Fisher, A. J. Phys. Chem. A 2001, 105, $2173-$ 2182.

[37] Sha, X.; Jackson, B.; Lemoine, D. J. Chem. Phys. 2002, 116, 7158-7169.

[38] Somers, M. F.; Kingma, S. M.; Pijper, E.; Kroes, G. J.; Lemoine, D. Chem. Phys. Lett. 2002, 360 , 390-399.

[39] Nave, S.; Lemoine, D.; Somers, M. F.; Kingma, S.M.; Kroes, G. J. J. Chem. Phys. 2005, 122, 214709-1-9.

[40] Martin-Gondre, L.; Crespos, C.; Larrégaray, P.; Rayez, J. C.; van Ootegem, B.; Conte, D. Chem. Phys. Lett. 2009, 471, 136-142.

[41] Volpilhac, G.; Salin, A. Surf. Sci. 2004, 556, 129-144.

[42] Alducin, M.; Díez-Muiño, R.; Busnengo, H. F.; Salin, A. J. Chem. Phys. 2006, 125, 144705-1-10.

[43] Martin-Gondre, L.; Crespos, C.; Larrégaray, P.; Rayez, J. C.; Conte, D.; van Ootegem, B. Chem. Phys. 2010, 367, 136-147.

[44] Martin-Gondre, L.; Crespos, C.; Larrégaray, P.; Rayez, J. C.; van Ootegem, B.; Conte, D. J. Chem. Phys. 2010, 132, 204501-1-11.

[45] Martin-Gondre, L.; Crespos, C.; Larrégaray, P.; Rayez, J. C.; Volphilac, G.; Salin, A. (to be published).

[46] Morón, V.; Martin-Gondre, L.; Crespos, C.; Larregaray, P.; Gamallo, P.; Sayós, R. Comput.

Theor. Chem. 2012 (in press), DOI: 10.1016/j.comptc.2012.01.030.

[47] Kresse, G.; Hafner, J. Phys. Rev. B 1993, 47, 558-561. 
[48] Kresse, G.; Hafner, J. Phys. Rev. B 1994, 49, 14251-14269.

[49] Kresse, G.; Furthmüller, J. Comput. Mater. Sci. 1996, 6, 15-50.

[50] Kresse, G.; Furthmüller, J. Phys. Rev. B 1996, 54, 11169-11186.

[51] Hammer, B.; Hansen, L. B.; Nørskov, J. K. Phys. Rev. B 1999, 59, 7413-7421.

[52] Blöchl, P. E. Phys. Rev. B 1994, 50, 17953-17979.

[53] Kresse, G.; Joubert, D. Phys. Rev. B 1999, 59, 1758-1775.

[54] Monkhorst, H. J.; Pack, J. D. Phys. Rev. B 1976, 13, 5188-5192.

[55]Gaussian 09, Revision A.1, M. J. Frisch, G. W. Trucks, H. B. Schlegel, G. E. Scuseria, M. A. Robb, J. R. Cheeseman, G. Scalmani, V. Barone, B. Mennucci, G. A. Petersson et al., Gaussian, Inc., Wallingford CT, 2009.

[56] Billing, G. D. Dynamics of Molecule Surface Interactions, John Wiley \& Sons: New York, 2000 (Chap. 5 and 6).

[57] Tully, J. C. J. Chem. Phys. 1980, 73, 1975-1985.

[58] Polanyi, J. C.; Wolf, R. J. J. Chem. Phys. 1985, 82, 1555-1566.

[59] Busnengo, H. F.; Di Cesare, M. A.; Dong, V.; Salin, A. Phys. Rev. B 2005, 72, 125411-125419.

[60] Pineau, N.; Busnengo, H.F.; Rayez, J.C..; Salin, A. J. Chem. Phys. 2005, 122, 214705-1-9.

[61] Groenenboom, G.; Struniewicz, I. J. Chem. Phys. 2000, 113, 9562-9566.

[62] Huber, K.; Herzberg, G. Constants of Diatomic Molecules, Van Nostrand Reinhold Company: New York, 1979.

[63] Busnengo, H. F.; Martínez, A. E. J. Phys. Chem. C 2008, 112, 5579-5588.

[64] Bae, C. S.; Freeman, D. L.; Doll, J. D.; Kresse, G.; Hafner, J. J. Chem. Phys. 2000, 113, 69266932.

[65] Busnengo, H. F.; Dong, W.; Salin, A. Chem. Phys. Lett. 2000, 320, 328-334.

[66] Arasa, C.; Busnengo, H. F.; Salin, A.; Sayós, R. Surf. Sci. 2008, 602, 975-985.

[67] Martinazzo, R.; Assoni, S.; Marinoni, G.; Tantardini, G. F. J. Chem. Phys. 2004, 120, 8761-8771.

[68] Morón, V.; Gamallo, P.; Martin-Gondre, L.; Sayós, R. manuscript in preparation. 